This PDF is a selection from an out-of-print volume from the National Bureau of Economic Research

Volume Title: Monetary Policy Rules

Volume Author/Editor: John B. Taylor, editor

Volume Publisher: University of Chicago Press

Volume ISBN: 0-226-79124-6

Volume URL: http://www.nber.org/books/tayl99-1

Publication Date: January 1999

Chapter Title: Forward-Looking Rules for Monetary Policy

Chapter Author: Nicoletta Batini, Andrew Haldane

Chapter URL: http://www.nber.org/chapters/c7416

Chapter pages in book: (p. 157 - 202) 


\title{
4 \\ Forward-Looking Rules for Monetary Policy
}

\author{
Nicoletta Batini and Andrew G. Haldane
}

\subsection{Introduction}

It has long been recognized that economic policy in general, and monetary policy in particular, needs a forward-looking dimension. "If we wait until a price movement is actually afoot before applying remedial measures, we may be too late," as Keynes (1923) observes in A Tract on Monetary Reform. That same constraint still faces the current generation of monetary policymakers. Alan Greenspan's Humphrey-Hawkins testimony in 1994 summarizes the monetary policy problem thus: "The challenge of monetary policy is to interpret current data on the economy and financial markets with an eye to anticipating future inflationary forces and to countering them by taking action in advance." Or in the words of Donald Kohn (1995) at the Board of Governors of the Federal Reserve System: "Policymakers cannot avoid looking into the future." Empirically estimated reaction functions suggest that policymakers' actions match these words. Monetary policy in the G-7 countries appears in recent years to have been driven more by anticipated future than by lagged actual outcomes (Clarida and Gertler 1997; Clarida, Galí, and Gertler 1998; Orphanides 1998).

But how best is this forward-looking approach made operational? Friedman's (1959) Program for Monetary Stability cast doubt on whether it could

Nicoletta Batini is analyst in the Monetary Assessment and Strategy Division, Monetary Analysis, Bank of England. Andrew G. Haldane is senior manager of the International Finance Division, Bank of England.

The authors have benefited greatly from the comments and suggestions of Bill Allen, Andy Blake, Willem Buiter, Paul Fisher, Charles Goodhart, Mervyn King, Paul Levine, Tiff Macklem, David Miles, Stephen Millard, Alessandro Missale, Paul Mizen, Darren Pain, Joe Pearlman, Richard Pierse, John Taylor, Paul Tucker, Ken Wallis, Peter Westaway, John Whitley, Stephen Wright, and especially discussant Don Kohn and other seminar participants. The views expressed within are not necessarily those of the Bank of England. 
be. Likening economic forecasting to weather forecasting, he observes: "Leaning today against next year's wind is hardly an easy task in the present state of meteorology." Yet this is just the task present-day monetary policymakers have set themselves: in effect, long-range weather forecasting in a stochastic world of time-varying lags and coefficients. That is a tough nut to crack even for meteorologists. It is not altogether surprising, then, that solving the equivalent problem in a monetary policy context has met with different solutions among central banks.

The more innovative among these solutions have recently been adopted by countries targeting inflation directly. These countries now include New Zealand, Canada, the United Kingdom, Sweden, Finland, Australia, and Spain (see Haldane 1995; Leiderman and Svensson 1995). In the first three of these countries, monetary policy is based on explicit (and in some cases published) inflation forecasts. ${ }^{1}$ These forecasts are the de facto intermediate or feedback variable for monetary policy (Svensson 1997a, 1997b; Haldane 1997). The aim of this paper is to evaluate that particular approach to the general problem of the need for forward-lookingness in monetary policy.

This is done by evaluating a class of simple policy rules that feed back from expected values of future inflation - inflation-forecast-based rules. These rules are simple, and so are analogous to the Taylor rule specifications that have recently been extensively discussed in an academic and policy-making context. Because they are forecast based, the rules mimic (albeit imperfectly) monetary policy behavior among inflation-targeting central banks in practice. ${ }^{2}$ And despite their simplicity, these forecast-based rules have a number of desirable features, which mean they may approximate the optimal feedback rule.

The class of forecast-based rules that we consider take the following generic form:

$$
r_{t}=\gamma r_{t-1}+(1-\gamma) r_{t}^{*}+\theta\left(E_{t} \pi_{t+j}-\pi^{*}\right),
$$

where $r_{t}$ denotes the short-term ex ante real rate of interest, $r_{t} \equiv i_{t}-E_{t} \pi_{t+1}$, where $i_{t}$ are nominal interest rates; $r_{t}^{*}$ denotes the equilibrium value of real interest rates; $E_{t}(\cdot)=E\left(\cdot \mid \Phi_{t}\right)$, where $\Phi_{t}$ is the information set available at time $t$ and $E$ is the mathematical expectations operator; $\pi_{t}$ is inflation $\left(\pi_{t} \equiv p_{t}^{\mathrm{c}}-\right.$ $p_{t-1}^{\mathrm{c}}$, where $p_{t}^{\mathrm{c}}$ is the $\log$ of the consumer price index); and $\pi^{*}$ is the inflation target. $^{3}$

According to the rule, the monetary authorities control deterministically nominal interest rates $\left(i_{t}\right)$ so as to hit a path for the short-term real interest rate

1. In the other inflation-targeting countries, inflation forecasts are sometimes less explicit but nevertheless a fundamental part of the monetary policy process.

2 . We discuss below the places in which the forecast-based rules we consider deviate from realworld inflation targeting.

3. The rule could be augmented with other-e.g., explicit output-terms. We do so below. This then takes us close to the reaction function specification found by Clarida et al. (1998) to match recent monetary policy behavior in the G-7 countries. 
$\left(r_{t}\right)$. Short real rates are in turn set relative to some steady state value, determined by a weighted combination of lagged and equilibrium real interest rates. The novel feature of the rule, however, is the feedback term. Deviations of expected inflation (the feedback variable) from the inflation target (the policy goal) elicit remedial policy actions.

The policy choice variables for the authorities are the parameter triplet $\{j, \theta, \gamma\}$. The parameter $\gamma$ dictates the degree of interest rate smoothing (see Williams 1997). So, for example, with $\gamma=0$ there is no instrument smoothing. The parameter $\theta$ is a policy feedback parameter. Higher values of $\theta$ imply a more aggressive policy response for a given deviation of the inflation forecast from its target. Finally, $j$ is the targeting horizon of the central bank when forming its forecast. For example, in the United Kingdom the Bank of England feeds back from an inflation forecast around two years ahead (King 1997). ${ }^{4}$ The horizon of the inflation forecast $(j)$ and the size of the feedback coefficient $(\theta)$, as well as the degree of instrument smoothing $(\gamma)$, dictate the speed at which inflation is brought back to target following inflationary disturbances. Because they influence the inflationary transition path, these policy parameters clearly also have a bearing on output dynamics.

As defined in equation (1), inflation targeting amounts to a well-defined monetary policy rule. That view is not at odds with Bernanke and Mishkin's (1997) characterization of inflation targeting as "constrained discretion." There is ample scope for discretionary input into any rule-equation (1) particularly so. These discretionary choices include the formation of the inflation expectation itself and the choice of the parameter set $\left\{j, \theta, \pi^{*}\right\}$. They mean that equation (1) does not fall foul of the critique of inflation targeting made by Friedman and Kuttner (1996): that it is rigid as a monetary strategy and hence destined to the same failures as, for example, strict monetary targeting.

This is fine as an intuitive description of a forecast-based policy rule such as rule (1). But what, if any, theoretical justification do these rules have? And, in particular, why might they be preferred to, for example, Taylor rules? Several authors have recently argued that, in certain settings, expected-inflationtargeting rules have desirable properties (inter alia, King 1997; Svensson 1997a, 1997b; Haldane 1998). For example, in Svensson's model (1997a), the optimal rule when the authorities care only about inflation is one that sets interest rates so as to bring expected inflation into line with the inflation target at some horizon ("strict" inflation-forecast targeting). When the authorities care also about output, the optimal rule is to less than fully close any gap between expected inflation and the inflation target ("flexible" inflation-forecast targeting). ${ }^{5}$

The rules we consider here differ from those in Svensson (1997a) in that

4. This comparison is not exact because $j$ defines the feedback horizon under the rule, whereas in practice in the United Kingdom two years refers to the policy horizon (the point at which expected inflation and the inflation target are in line).

5. Rudebusch and Svensson consider empirically rules of this sort in chap. 5 of this volume. 
they are simple feedback rules for the policy instrument, rather than complicated optimal targeting rules. Simple feedback rules have some clear advantages. First, they are directly analogous to, and so comparable with, the other policy rule specifications discussed in the papers in this volume, including Taylor rules. Second, simple rules are arguably more robust when there is uncertainty about the true structure of the economy. And third, simple rules may be advantageous on credibility and monitorability grounds (Taylor 1993). The last of these considerations is perhaps the most important in a policy context, for one way to interpret the output from these rules is as a cross-check on actual policy in real time. For that to be practical, any rule needs to be simple and monitorable by outside agents.

At the same time, the simple forecast-based rules we consider do have some clear similarities with Svensson's optimal inflation-forecast-targeting rules. Monetary policy under both rules seeks to offset deviations between expected inflation and the inflation target at some horizon. ${ }^{6}$ More concretely, even simple forecast-based specifications can be considered "encompassing" rules, in the following respects:

Lag Encompassing. The lag between the enactment of monetary policy and its first effects on inflation and output are well known and widely documented. The monetary authorities need to be conscious of these lags when framing policy; they need to be able to calibrate them reasonably accurately; and they then need to embody them in the design of their policy rules. Without this, monetary policy will always be acting after the point at which it can hope to head off incipient inflationary pressures. Such myopic policy may itself then become a source of cyclical (in particular, inflation) instability, for the very reasons outlined by Friedman (1959). ${ }^{7}$

By judicious choice of $j$, the lead term on expected inflation in equation (1), simple forecast-based rules can be designed so as to embody automatically these transmission lags. In particular, the feedback variable in the rule can be chosen so that it is directly under the control of the monetary authoritiesinflation $j$ periods hence. The policymakers' feedback and control variables are then explicitly aligned. Transmission lags are the most obvious (but not the only) reason why monetary policy needs a forward-looking, preemptive dimension. Embedding these lags in a formal forecast-based rule is simple recognition of that fact. ${ }^{8}$ Reflecting this, lag encompassing was precisely the motiva-

6. In particular, since the rules we consider allow flexibility over both the forecast horizon $(j)$ and the feedback parameter $(\theta)$ - both of which affect output stabilization - their closest analogue is Svensson's flexible inflation-forecast-targeting rule.

7. Former vice-chairman of the Federal Reserve Alan Blinder observes: "Failure to take proper account of lags is, I believe, one of the main sources of central bank error" (1997).

8. Svensson (1997a) shows, in the context of his model, that rules with this lag-encompassing feature secure the minimum variance of inflation precisely because they guard against monetary policy acting too late. 
tion behind targeting expected inflation in those countries where this was first adopted: New Zealand, Canada, and the United Kingdom.

Information Encompassing. Under inflation-forecast-based rules, the inflation expectation in rule (1) can be thought of as the intermediate variable for monetary policy. It is well suited to this task when judged against the three classical requirements of any intermediate variable: it is controllable, predictable, and a leading indicator. Expected inflation is, almost by definition, the indicator most closely correlated with the future value of the variable of interest. In particular, expected inflation ought to embody all information contained within the myriad indicators that affect the future path of inflation. Forecast-based rules are, in this sense, information encompassing. That is not a feature necessarily shared by backward-looking policy rules-for example, those considered in the volume by Bryant, Hooper, and Mann (1993).

Of course, any forward-looking rule can be given a backward-looking representation and respecified in terms of current and previously dated variables. For example, in the aggregate-demand/aggregate-supply model of Svensson (1997a), the optimal forward-looking rule can be rewritten as a Taylor rulealbeit with weights on the output gap and inflation that are likely to be very different from one-half. But that will not necessarily be the case in more general settings where shocks come not just from output and prices. Taylor-type rules will tend then to feed back from a restrictive subset of information variables and so will not in general be optimal. ${ }^{9}$ By contrast, inflation-forecastbased rules will naturally embody all information contained in the inflation reduced-form of the model: extra lags of existing predetermined variables and additional predetermined variables, both of which would typically also enter the optimal feedback rule. For that reason even simple forecast-based rules are likely to take us close to the optimal state-contingent rule-or at least closer than Taylor-type rule specifications.

Output Encompassing. As specified in equation (1), inflation-forecast-based rules appear to take no explicit account of output objectives. The inflation target, $\pi^{*}$, defines the nominal anchor, and there is no explicit regard for output stabilization. But $\pi^{*}$ is not the only policy choice parameter in equation (1). The targeting horizon $(j)$ and feedback parameter $(\theta)$ - the two remaining policy choice variables - can in principle also help to secure a degree of output smoothing. These parameters can be chosen to ensure that an inflationforecast-based rule better reflects the authorities' preferences in situations where they care about output as well as inflation variability. To see how these policy parameters affect output stabilization, consider separately shocks to demand and supply. 
In the case of demand shocks, inflation and output stabilization will in most instances be mutually compatible. Demand shocks shift output and inflation in the same direction relative to their baseline values. So there need not then be any inherent trade-off between output and inflation stabilization in the setting of monetary policy following these shocks. A rule such as equation (1) will automatically secure a degree of output stabilization in a world of just demand shocks. Or, put differently, because it is useful for predicting future inflation, the output gap already appears implicitly in an inflation-forecast-based rule such as equation (1).

For supply shocks, trade-offs between output and inflation stability are more likely because they will tend then to be shifted in opposite directions. But inflation targeting does not imply that the authorities are opting for a corner solution on the output-inflation variability trade-off curve in these situations. For example, different inflation forecast horizons-different values of $j$-will imply different points on the output-inflation variability frontier. Longer forecast horizons smooth the transition of inflation back to target following inflation shocks, in part because policy then accommodates (rather than offsets) the first-round effects of any supply shocks. ${ }^{10}$ The feedback coefficient $(\theta)$ also has a bearing on output dynamics, for much the same reason. So a central bank following an inflation-forecast-based rule can, in principle, simply choose its policy parameters $\{j, \theta, \gamma\}$ so as to achieve a preferred point on the outputinflation variability spectrum. Certainly, the simple forecast-based policy rule (1) ought not to be the sole preserve of monomaniacal inflation fighters.

This paper aims to put some quantitative flesh onto this conceptual skeleton. It evaluates simple forecast-based rules against the three encompassing criteria outlined above. ${ }^{11}$ The type of policy questions this then enables us to address include: What is the optimal degree of policy forward-lookingness? And what does this depend on? Can inflation-only rules secure sufficient output smoothing? How do simple forecast-based rules compare with the fully optimal rule? And with simple Taylor rules?

To summarize our conclusions up front, we find quantitative support for all

10. This is broadly the practice followed in the United Kingdom. The Bank of England is required to write an open letter to the Chancellor in the event of inflation deviating by more than 1 percentage point from its target, stating the horizon over which inflation is to be brought back to heel. Longer horizons might be chosen following large or persistent supply shocks, so that policy does not disturb output too much en route back to the inflation target. That is important because the United Kingdom's inflation target, while giving primacy to price stability, also requires that the Bank of England take account of output and employment objectives when setting monetary policy. Other design features of inflation targets can ensure a sufficient degree of output stabilization. E.g., in New Zealand there are inflation target exemptions for "significant" supply shocks (see Mayes and Chapple 1995); while in Canada there is a larger inflation fluctuation margin to help insulate against shocks (see Freedman 1996).

11. Previous empirical simulation studies that have considered the performance of forwardlooking rules include Black et al. (1997), Clark, Laxton, and Rose (1995), and Brouwer and O'Regan (1997). 
three of the encompassing propositions. Because inflation-forecast-based policy rules embody transmission lags, they generally help improve inflation control (lag encompassing). These rules can be designed to smooth the path of output as well as inflation, despite not feeding back from the former explicitly (output encompassing). And inflation-forecast-based rules deliver clear welfare improvements over Taylor-type rules, which respond to a restrictive subset of information variables (information encompassing).

The paper is planned as follows. Section 4.2 outlines our model. Section 4.3 calibrates this model and conducts some deterministic experiments with it. Section 4.4 uses stochastic analysis to evaluate the three conceptual properties of forecast-based rules-lag encompassing, information encompassing, and output encompassing — outlined above. Section 4.5 briefly summarizes.

\subsection{The Model}

To evaluate equation (1), and variants of it, we use a small open economy, log-linear calibrated rational expectations macromodel. It has similarities with the optimizing IS-LM framework recently developed by McCallum and Nelson (forthcoming) and Svensson (forthcoming), and hence indirectly with the stochastic general equilibrium models of Rotemberg and Woodford (1997) and Goodfriend and King (1997). The open economy dimension is important when characterizing the behavior of inflation-targeting countries, which tend to be just such small open economies (see Blake and Westaway 1996; Svensson, forthcoming). The exchange rate also has an important bearing on outputinflation dynamics in our model, in keeping with the results of Ball (chap. 3 of this volume). Having a pseudostructural model is important too, given the susceptibility of counterfactual policy simulations to Lucas critique problems.

The model is kept deliberately small to ease the computational burden. But a compact model is also useful in helping clarify the transmission mechanism channels at work and the trade-offs that naturally arise among them. And despite its size, the model embodies the key features of the small forecasting model used by the Bank of England for its inflation projections. The model is calibrated to match the dynamic path of output and inflation generated by structural and reduced-form models of the United Kingdom economy in the face of various shocks.

The model comprises six behavioral relationships, listed as equations (2) through (7) below:

$$
\begin{aligned}
& y_{t}-y_{t}^{*}= \alpha_{1} y_{t-1}+\alpha_{2} E_{t}\left(y_{t+1}\right)+\alpha_{3}\left(i_{t}-E_{t} \pi_{t+1}\right) \\
&+\alpha_{4}\left(e_{t}+p_{t}^{\mathrm{c}}-p_{t}^{\mathrm{cf}}\right)+\varepsilon_{1 t}, \\
& m_{t}-p_{t}^{\mathrm{c}}=\beta_{1} y_{t}+\beta_{2} i_{t}+\varepsilon_{2 t}, \\
& e_{t}=E_{t} e_{t+1}+i_{t}-i_{t}^{\mathrm{f}}+\varepsilon_{3 t},
\end{aligned}
$$




$$
\begin{gathered}
p_{t}^{\mathrm{d}}=1 / 2\left(w_{t}+w_{t-1}\right) \\
w_{t}-p_{t}^{\mathrm{c}}=\chi_{0}\left(E_{t} w_{t+1}-E_{t} p_{t+1}^{\mathrm{c}}\right)+\left(1-\chi_{0}\right)\left(w_{t-1}-p_{t-1}^{\mathrm{c}}\right) \\
+\chi_{1}\left(y_{t}-y_{t}^{*}\right)+\varepsilon_{4 t} \\
p_{t}^{\mathrm{c}}=\phi p_{t}^{\mathrm{d}}+(1-\phi) e_{t}
\end{gathered}
$$

All variables, except interest rates, are in logarithms. Importantly, in the simulations all behavioral relationships are also expressed as deviations from equilibrium. So, for example, we set the (log) natural rate of output, $y_{f}^{*}$, equal to zero. We also normalize to zero the (log) foreign price level and foreign interest rate, $p_{t}^{\mathrm{cf}}=i_{t}^{\mathrm{f}}=0$, and the (implicit) markup in equation (5) and foreign exchange risk premium in equation (4).

Equation (2) is a standard IS curve, with real output, $y_{t}$, depending negatively on the ex ante real interest rate and the real exchange rate (where $e_{t}$ is the foreign currency price of domestic currency), $\left\{\alpha_{3}, \alpha_{4}\right\}<0$. The former channel is defined over short rather than long real interest rates. We could have included a long-term interest rate in our model, linking long and short rates through an arbitrage condition, as in Fuhrer and Moore's (1995a) model of the United States. But in the United Kingdom, unlike in the United States, expenditure is more sensitive to short than to long interest rates, owing to the prevalence of floating-rate debt instruments.

Output also depends on lags of itself, reflecting adjustment costs and, more interestingly, a lead term. The latter of these is motivated by McCallum and Nelson's (forthcoming) work on the form of the reduced-form IS curve that arises from a fully optimizing general equilibrium macromodel. We experiment with this lead term below, even though we do not use it in our baseline simulations. The term $\varepsilon_{l t}$ is a vector of demand shocks, for example, shocks to foreign output and fiscal policy.

Equation (3) is an LM curve. ${ }^{12}$ Its arguments are conventional: a nominal interest rate, capturing portfolio balance, and real output, capturing transactions demand. ${ }^{13}$ The term $\varepsilon_{2 t}$ is a vector of velocity shocks. Equation (4) is an uncovered interest parity condition. We do not include any explicit foreign exchange risk premium. The shock vector $\varepsilon_{3 t}$ comprises foreign interest rate shocks and other noise in the foreign exchange market, including shocks to the exchange risk premium.

Equations (5) and (6) define the model's supply side. They take a similar form to that of other staggered contract models. ${ }^{14}$ Equation (5) is a markup equation. Domestic output prices (in logs, $p_{t}^{\mathrm{d}}$ ) are a constant markup over weighted average contract wages (in logs, $w_{t}$ ) in the current and preceding peri-

12. This is largely redundant in our analysis since we are focusing on interest rate rules that assume that the demand for money is always fully accommodated at unchanged interest rates.

13. McCallum and Nelson (forthcoming) show that this form of the LM curve can also be derived as the reduced form of an optimizing stochastic general equilibrium model.

14. In particular, they are similar to those recently developed by Fuhrer and Moore (1995a) for the United States. For an early formulation of such model, see Buiter and Jewitt (1981). 
ods. Equation (6) is the wage-contracting equation. Under this specification, wage contracts last two periods. ${ }^{15}$ Agents in today's wage cohort bargain over relative real consumption wages. Today's real contract wage is some weighted average of the real contract wage of the "other" cohort of workers: that is, wages already agreed upon in the previous period and those expected to be agreed upon in the next period. We do not impose symmetry on the lag and lead terms in the contracting equation, as in the standard Fuhrer and Moore (1995b) model. Instead we allow a flexible mixed lag-lead specification, which nests more restrictive alternatives as a special case (see Blake 1996; Blake and Westaway 1996). This flexible mixed specification is found in Fuhrer (1997) to be preferred empirically. It also allows us to experiment with the degree of forward-lookingness in the wage-bargaining process. The lag-lead weights are restricted to sum to unity, however, to preserve price homogeneity in the wageprice system (a vertical long-run Phillips curve). Also in the wage-contracting equation is a conventional output gap term, capturing tightness in the labor market. The shock vector, $\varepsilon_{4 t}$, can be thought to capture disturbances to the natural rate of output and similar such supply shocks.

This relative wage-price specification has both theoretical and empirical attractions. Its theoretical appeal comes from work as early as Duesenberry (1949), which argued that wage relativities were a key consideration when entering the wage bargain. The empirical appeal of the relative real wage formulation is that it generates inflation persistence. This is absent from a conventional two-period Taylor (1980) contracting specification (Fuhrer and Moore 1995a; Fuhrer 1997), which instead produces price level persistence. ${ }^{16}$ Equation (7) defines the consumption price index, comprising domestic goods (with weight $\phi$ ) and imported foreign goods (with weight $1-\phi) .{ }^{17}$ Note that equation (7) implies full and immediate passthrough of import prices (and hence exchange rate changes) into consumption prices-an assumption we discuss further below.

Some manipulation of equations (5), (6), and (7) gives the reduced-form Phillips curve of the model:

$$
\begin{aligned}
\pi_{t}= & \chi_{0} E_{t} \pi_{t+1}+\left(1-\chi_{0}\right) \pi_{t-1}+\chi_{1}\left(y_{t}+y_{t-1}\right) \\
& +\mu\left[\left(1-\chi_{0}\right) \Delta c_{t}-\chi_{0} E_{t} \Delta c_{t+1}\right]+\varepsilon_{5 t},
\end{aligned}
$$

where $c_{t} \equiv e_{t}-p_{t}^{c}$ (the real exchange rate), $\mu \equiv 2(1-\phi), \Delta$ is the backward difference operator, and $\varepsilon_{5 t} \equiv \varepsilon_{4 t}+\chi_{0}\left[\left(p_{t}^{\mathrm{c}}-E_{t-1} p_{t}^{\mathrm{c}}\right)-\left(w_{t}-E_{t-1} w_{t}\right)\right]$, where the composite error now includes expectational errors by wage bargainers.

15. We could have lengthened the contracting lag-e.g., to four periods, which in our calibration is one year-to better match real-world behavior. But two lags appeared to be sufficient to generate the inflation persistence evident in the data, when taken together with the degree of backward-lookingness embodied in the Phillips curve.

16. As Roberts (1995) discusses, Taylor contracting can deliver inflation persistence if, e.g., expectations are made "not quite rational." Certainly, a variety of mechanisms other than the one adopted here would have allowed us to introduce inflation persistence into the model.

17. With the foreign price level normalized to zero in logs. 
Equation (8) is the open economy analogue of Fuhrer and Moore's (1995a) Phillips curve specification (see Blake and Westaway 1996). The inflation terms-a weighted backward- and forward-looking average-are the same as in the closed economy case. There is inflation persistence. The specification differs because of additional (real) exchange rate terms, reflecting the price effects of exchange rate changes on imported goods in the consumption basket. ${ }^{18}$

The transmission of monetary impulses in this model is very different from the closed economy case, in terms of size and timing of the effects: we illustrate these effects below. There is a conventional real interest rate channel, working through the output gap and thence onto inflation. But in addition there is a real exchange rate effect, operating through two distinct channels. First, there is an indirect output gap route running through net exports and thence onto inflation. And second, there are direct price effects via the cost of imported consumption goods and via wages and hence output prices. The latter channel means that disinflation policies have a speedy effect on consumer prices $\left(p_{t}^{c}\right)$, if not on domestically generated prices $\left(p_{t}^{d}\right)$ - see Svensson (forthcoming). This direct exchange rate channel thus has an important bearing on consumer price inflation and output dynamics, which we illustrate below. Because these direct exchange rate effects derive from the (potentially restrictive) assumption of full and immediate passthrough of exchange rate changes to consumption prices, however, we also experiment below with a model where passthrough is sluggish or incomplete. This specification might be more realistic if, for example, we believe that foreign exporters "price to market," holding the foreign currency prices of their exported goods relatively constant in the face of exchange rate changes, or if home-country retail importers absorb the effects of exchange rate changes in their margins.

The model (2)-(7) is clearly not structural in the sense that we can back out directly from its taste and technology parameters. Nevertheless, as McCallum and Nelson (forthcoming) have recently shown, a system such as (2)-(7) can be derived as the linear reduced-form of a fully optimizing general equilibrium model, under certain specifications of tastes and technology. That ought to confer some degree of policy invariance on model parameters-and hence some immunity from the Lucas critique.

\subsection{Deterministic Policy Analysis}

\subsubsection{Calibrating the Model}

To assess the properties of the model described above, we begin with some deterministic simulations. For this we need to calibrate the behavioral parameters in equations (2) through (7). As far as possible, we set our baseline cali-

18. Plus the effects of the composite error term. 
brated values in line with prior empirical estimates on quarterly data. Where this is not possible - for example, in the wage-contracting equation-we calibrate parameters to ensure a plausible dynamic profile from impulse responses. We also experiment below, however, with some deviations from the baseline parameterization, in particular the degree of forward-lookingness in the model.

For the IS curve (2), we set $\alpha_{1}=0.8$, which is empirically plausible on quarterly data. For the moment we set $\alpha_{2}=0$, ignoring until later any direct forward-lookingness in the IS curve. We set the real interest rate $\left(\alpha_{3}\right)$ and real exchange rate $\left(\alpha_{4}\right)$ elasticities to -0.5 and -0.2 , respectively. Both are in line with empirical estimates from the Bank of England's forecasting model. For the LM curve we set $\beta_{1}=1$ and $\beta_{2}=0.5$, so that money is unit income elastic and has an interest semielasticity of one-half. Both of these restrictions are broadly satisfied on U.K. data (Thomas 1996).

On the contracting equation (6), our baseline model sets $\chi_{0}=0.2$, so that contracting is predominantly backward looking. This specification matches the pattern of the data much better than an equally weighted formulation, both in the United States (Fuhrer 1997) and in the United Kingdom (Blake and Westaway 1996).$^{19}$ The output sensitivity of real wages is set at $0.2\left(\chi_{1}=0.2\right)$, in line with previous studies. ${ }^{20}$ We set $\phi$, the share of domestically produced goods in the consumption basket, equal to 0.8 , in line with existing shares.

Turning to the policy rule (1), for consistency with the model this is also simulated as a deviation from equilibrium. That is, we set $\pi^{*}$ (the inflation target) and $r_{t}^{*}$ (the equilibrium real rate) to zero. Because of this, our simulations do not address questions regarding the optimal level of $\pi^{*}$. For example, our model does not broach issues such as the stabilization difficulties caused by the nonnegativity of nominal interest rates. We are implicitly assuming that the level of $\pi^{*}$ has been set such that this constraint binds with only a negligibly small probability. Nor do we address issues such as time variation in $r_{t}^{*}$.

In terms of the parameter triplet $\{j, \theta, \gamma\}$, in our baseline rule we set $\gamma=$ 0.5 - a halfway house between the two extreme values of interest rate smoothing we consider; $\theta=0.5$-around the middle of the range of feedback parameters used in previous simulation studies (Taylor 1993a; McCallum 1988; Black et al. 1997); and $j=8$ periods. Because the model is calibrated to match quarterly profiles for the endogenous variables, this final assumption is equivalent to targeting the quarterly inflation rate two years ahead. This is around the horizon from which central banks feed back in practice. For example, the Bank of England's "policy rule" has been characterized as targeting the inflation rate two years or so ahead (King 1996). ${ }^{21}$

19. The lag-lead weights chosen here are very similar to those found empirically in the United States by Fuhrer (1997).

20. The elasticity of real wages is close to that found by Fuhrer (1997) in the United States of 0.12 .

21. Though the United Kingdom's inflation target is defined as an annual percentage change in price levels, which means that this comparison is not exact: see below. 
Because the model (2)-(7) and the baseline policy rule (1) are log-linear, we can solve the system using the method of Blanchard and Kahn (1980). Denote the vector of endogenous variables $\mathbf{z}_{\mathbf{t}}{ }^{22}$ The model (1)-(7) has a convenient state-space representation,

$$
\left[\begin{array}{c}
\mathbf{q}_{\mathbf{t}+1} \\
E_{t} \mathbf{x}_{\mathbf{t}+1}
\end{array}\right]=\mathbf{A}\left[\begin{array}{l}
\mathbf{q}_{\mathbf{t}} \\
\mathbf{x}_{\mathbf{t}}
\end{array}\right]+\mathbf{B} \boldsymbol{\varepsilon}_{\mathbf{t}},
$$

where $\mathbf{q}_{\mathbf{t}}$ is a vector containing $\mathbf{z}_{\mathbf{t}-1}$ and its lags, $\mathbf{x}_{\mathbf{t}}$ is a vector containing $\mathbf{z}_{\boldsymbol{t}}$, $E_{t} \mathbf{z}_{\mathbf{t}+1}, E_{t} \mathbf{z}_{\mathbf{t}+2}$, and so forth, and, as usual, $E_{t}$ is the expectations operator using information up to time $t$. The solution to equation (9) is obtained by implementing the Blanchard and Kahn (1980) method with a standard computer program that solves linear rational expectations models. ${ }^{23}$ This program imposes the condition that there are no explosive solutions, implying a relationship $E_{t} \mathbf{x}_{\mathbf{t}+1}+\mathbf{N q}_{\mathbf{t + 1}}=0$, where [N I] is the set of eigenvectors of the stable eigenvalues of $\mathbf{A}$.

We then evaluate the various rules by conducting stochastic policy simulations and calculating in each case unconditional moments of the endogenous variables. To conduct the simulations we need a covariance matrix of the shocks for the exogenous variables.

There are a variety of ways of generating these shocks. The theoretical model (2)-(7) does not have enough dynamic structure to believe that its empirically estimated residuals are legitimate measures of primitive shocks. Alternatively, and at the other end of the spectrum, we could use atheoretic time series or vector autoregression (VAR) models to construct structural shocks. But that approach is not without problems either. Identification restrictions are still required to unravel the structural shocks from the reduced-form VAR residuals. Because these restrictions are just-identifying, they are nontestable. Further, in the VAR literature these restrictions usually include orthogonality of the primitive disturbances, $E_{t}\left(\boldsymbol{\varepsilon}_{\mathrm{it}} \mathbf{e}_{\mathbf{j t}}{ }^{\prime}\right)=0$ for all $i \neq j$. That is not a restriction we would want necessarily to impose a priori. ${ }^{24}$

We steer a middle course between these alternatives, using a covariance matrix of structural shocks derived from the Bank of England's forecasting model. ${ }^{25}$ This confers some advantages. First, and importantly, our analytical model can be considered a simplified version of this forecasting model, only without its dynamic structure. This lends some coherence to the deterministic and stochastic parts of the analysis. Second, the structural shocks from the forecasting model permit nonzero covariances.

For IS, LM, and Phillips curve shocks, we simply take the moments of the

22. Boldface denotes vectors and matrices.

23. This was conducted within the ACES/PRISM solution software (Gaines, Al'Nowaihi, and Levine 1989).

24. Though see Leeper, Sims, and Zha (1996). Black et al. (1997) generate identified VAR residuals without imposing this restriction.

25. This matrix is available from the authors on request. 
residuals from the Bank's forecasting model over the sample period 1989:197:3. Our sample period excludes most of the 1970s and 1980s, during which time the variance of shocks for all of the variables was (sometimes considerably) higher. Using a longer sample period would rescale upward the variances we report. The exchange rate is trickier. For that, we use quarterly Money Market Services Inc. survey data to capture exchange rate expectations over our sample, using the dollar-pound exchange rate as our benchmark. ${ }^{26}$ The exchange rate residuals were then constructed from the arbitrage condition (4), plugging in the survey expectations and using quarterly data for the other variables. Not surprisingly, the resulting exchange rate shock vector has a large variance, around 10 times that of the IS, LM, and Phillips curve shocks. Given its size, we conducted some sensitivity checks on the exchange rate variance. Rescaling the variance does not alter the conclusions we draw about the relative performance of the rules.

\subsubsection{A Disinflation Experiment}

To assess the plausibility of the system's properties, we displaced deterministically the intercept of each equation in the model (the IS equation, the money demand equation, the aggregate supply equation, and the exchange rate equation) by 1 percent and traced out in each case the resulting impulse response. Each of these impulse responses gave dynamic profiles that were theoretically plausible. For example, a permanent negative supply shock-a rise in the NAIRU, say - shifted inflation and output in opposite directions on impact and lowered output below baseline in steady state; whereas a permanent positive demand shock - a rise in overseas demand, say-shifted output and inflation in the same direction initially but was output neutral in steady state.

To illustrate the calibrated model's dynamic properties, consider the effects of a shock to the reaction function (1). Consider in particular a disinflationa lowering of the inflation target, $\pi^{*}$ - of 1 percentage point. The solid lines in figure 4.1 plot the responses of output and inflation to this inflation target shock. Impulse response profiles are shown as percentage point deviations from baseline values.

The economy has returned to steady state after around 16 quarters (four years). At that point, inflation is 1 percentage point lower at its new target and output is back to potential. But the transmission process in arriving at this endpoint is protracted. Output is below potential for the whole of the period, with a maximum marginal effect of around 0.2 percentage points after around 5 quarters. Output falls partly as a result of a policy-induced rise in real interest rates (of around 0.14 percentage points) and partly as a result of the accompanying real exchange rate appreciation (of around 0.57 percentage points). The

26. A preferred exchange rate measure would have been the United Kingdom's trade-weighted effective index. But there are no survey data on exchange rate expectations of this index. We also looked at the behavior of the deutsche mark-pound and yen-pound exchange rates. The variance of the dollar-pound residuals was somewhere between that of mark-pound and yen-pound. 

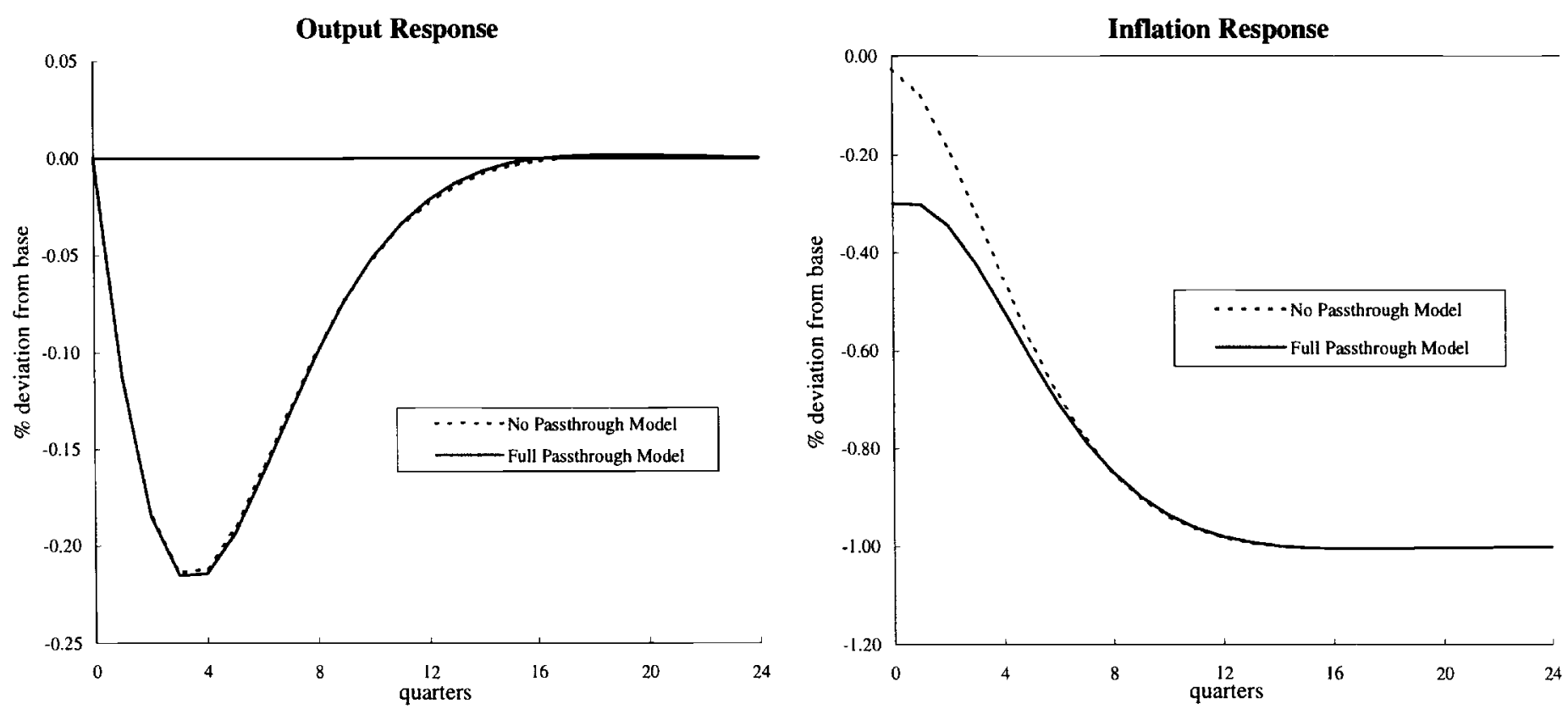

Fig. 4.1 Output and inflation responses to inflation target shock 
path of output and its maximum response are broadly in line with simulation responses from VAR-based studies of the effects of monetary policy shocks in the United Kingdom (Dale and Haldane 1995) ${ }^{27}$ The cumulative loss of output - the sacrifice ratio-is around 1.5 percent. This sacrifice ratio estimate is not greatly out of line with previous U.K. estimates (Bakhshi, Haldane, and Hatch 1999) but is if anything on the low side (see below).

Inflation undergoes an initial downward step owing to the impact effect of the exchange rate appreciation on import prices. Although the effect of the exchange rate shock is initially to alter the price level, this effect gets embedded in wage-bargaining behavior and so has a durable impact on measured inflation. Thereafter, inflation follows a gradual downward path toward its new target, under the impetus of the negative output gap. The inflation profile and in particular the immediate step jump in inflation following the shock are not in line with prior reduced-form empirical evidence on the monetary transmission mechanism.

The simulated inflation path is clearly sensitive to the assumptions we have made about exchange rate passthrough - namely, that it is immediate and complete. In particular, it is the full-passthrough assumption that lies behind the initial jump in inflation following a monetary disturbance. So one implication of this assumption is that monetary policy in an open economy can affect consumer price inflation with almost no lag (Svensson, forthcoming). There may well of course be adverse side effects from an attempt to control inflation in this way, such as real exchange rate and hence output destabilization. We illustrate these side effects below. But more fundamentally, the monetary transmission lag, and hence the implied degree of inflation control, is clearly acutely sensitive to the exchange rate passthrough assumption we have made.

As a sensitivity check, the dotted lines in figure 4.1 show the responses of output and inflation if we assume no direct exchange rate passthrough into consumer prices ${ }^{28}$ Monetary policy impulses are then all channeled through output, either via the real interest rate or via the real exchange rate. The resulting output path is little altered. But as we might expect, the downward path of inflation is more sluggish, mimicking the output gap. It is in fact now rather closer to that found from VAR-based studies of the effects of monetary policy in the United Kingdom. Given the clear sensitivity of the inflation profile to the passthrough assumption, we use both passthrough models below when considering the effects of transmission lags on the optimal degree of policy forward-lookingness.

27. Though the shocks are not exactly the same.

28. Which we reproduce by assuming the import content of the consumption basket is zero. This would be justified if, e.g., all imported goods were intermediate rather than final goods or, more generally, if the effects of exchange rate changes were absorbed in foreign exporters' or domestic retailers' margins rather than in domestic currency consumption prices. See Svensson (forthcoming) for a comparison of inflation-targeting rules based on consumer and producer prices. 


\subsubsection{Some Limitations of the Simulations}

The impulse responses suggest that our model is a reasonable dynamic representation of the effects of monetary policy in a small open economy such as the United Kingdom, Canada, or New Zealand-the three longest-serving inflation targeters. Nevertheless, the simulated model responses are clearly a simplified and stylized characterization of inflation targeting as exercised in practice. Two limitations in particular are worth highlighting.

First, we impose model consistency on all expectations, including the inflation expectations formed by the central bank that serve as its policy feedback variable. This is coherent as a simulation strategy, as otherwise we would have to posit some expectational mechanism that was potentially different from the model in which the policy rule was being embedded. But the assumption of model-consistent expectations has drawbacks too. For example, it underplays the role of model uncertainties. These uncertainties are important, but a consideration of them is beyond the scope of the present paper. Further, the simulations assume that the inflation target is perfectly credible. So the shock to the target shown in figure 4.1 is, in effect, believed fully and immediately. This helps explain why the sacrifice ratio implied by figure 4.1 is lower than historical estimates; it is the full-credibility case. While the assumption of full credibility is limiting, it is not obvious that it should affect greatly our inferences about the relative performance of various rules, which is the focus of the paper.

Second, and relatedly, under model-consistent expectations monetary policy is assumed to be driven by the specified policy rule. In particular, the inflation forecast of the central bank - the policy feedback variable - is conditioned on the inflation-targeting policy rule (1). This differs somewhat from actual central bank practice in some countries. For example, in the United Kingdom the Bank of England's published inflation forecasts are usually conditioned on an assumption of unchanged interest rates. ${ }^{29}$ This means that there is not a direct read-across from our forecast-based rules to inflation targeting in practice in some countries.

Even among those countries that use it, however, the constant interest rate assumption is seen largely as a short-term expedient. It is not appropriate, for example, when simulating a forward-looking model-as here-because it deprives the system of a nominal anchor and thus leaves the price level indeterminate. So in our simulations we instead condition monetary policy (actual and in expectation) on the reaction function (1). This delivers a determinate price level. Simulations conducted in this way come close to mimicking current monetary policy practice in New Zealand (Reserve Bank of New Zealand 1997). There, the Reserve Bank of New Zealand's policy projections are based on an explicit policy reaction function, which is very similar to the baseline

29. This is also often the case with forecasts produced for the Federal Reserve Board's "Green Book" (see Reifschneider, Stockton, and Wilcox 1996). 
rule (1). The Bank of England also recently began publishing inflation projections based on market expectations of future interest rates, rather than constant interest rates. This means that differences between the forecast-based rule (1) and inflation targeting in practice may not be so sharp.

\subsection{Stochastic Policy Analysis}

We now turn to consider the performance of the baseline rule (1) and compare it with alternative rules. This is done by embedding the various rules in the model outlined above and evaluating the resulting (unconditional) moments of output, inflation, and the policy instrument - the arguments typically thought to enter the central bank's loss function. Specifically, following Taylor (1993), we consider where each of the rules places the economy on the output-inflation variability frontier.

\subsubsection{Lag Encompassing: The Optimal Degree of Policy Forward-Lookingness}

The most obvious rationale for a forward-looking monetary policy rule is that it can embody explicitly the lags in monetary transmission. But how forward looking? Is there some optimal forecasting horizon from which to feed back? And, if so, what does this optimal targeting horizon depend on?

Answers to these questions are clearly sensitive to the assumed length of the lag itself. So we experiment below with both our earlier models: one assuming full and immediate import price passthrough (a shorter transmission lag), and the other no immediate passthrough (a longer transmission lag). Figure 4.2 plots the locus of output-inflation variability points delivered by the rule (1) as the horizon of the inflation forecast $(j)$ is varied. Two lines are plotted in figure 4.2 , representing the two passthrough cases. Along these loci, we vary $j$ between zero (current-period inflation targeting) and 16 (four-year-ahead inflation-forecast targeting) periods. ${ }^{30}$ Our baseline rule $(j=8)$ lies between these extremes. The two remaining policy choice parameters in rule $(1),\{\gamma, \theta\}$, are for the moment set at their baseline values of $0.5 .{ }^{31}$ Points to the south and west in figure 4.2 are clearly welfare superior, and points to the north and east inferior.

Several points are clear from figure 4.2. First, irrespective of the assumed degree of passthrough, the optimal forecast horizon is always positive and lies somewhere between three and six quarters ahead. This forecast horizon secures as good inflation performance as any other, while at the same time delivering lowest output variability. The latter result arises because three to six quarters is around the horizon at which monetary policy has its largest marginal

30. Some of the longer horizon feedback rules were unstable, which we discuss further below. In fig. 4.2 we show the maximum permissible feedback horizon: 14 periods for the fullpassthrough case and 12 periods for the no-passthrough case.

31. We vary them both in turn below. 


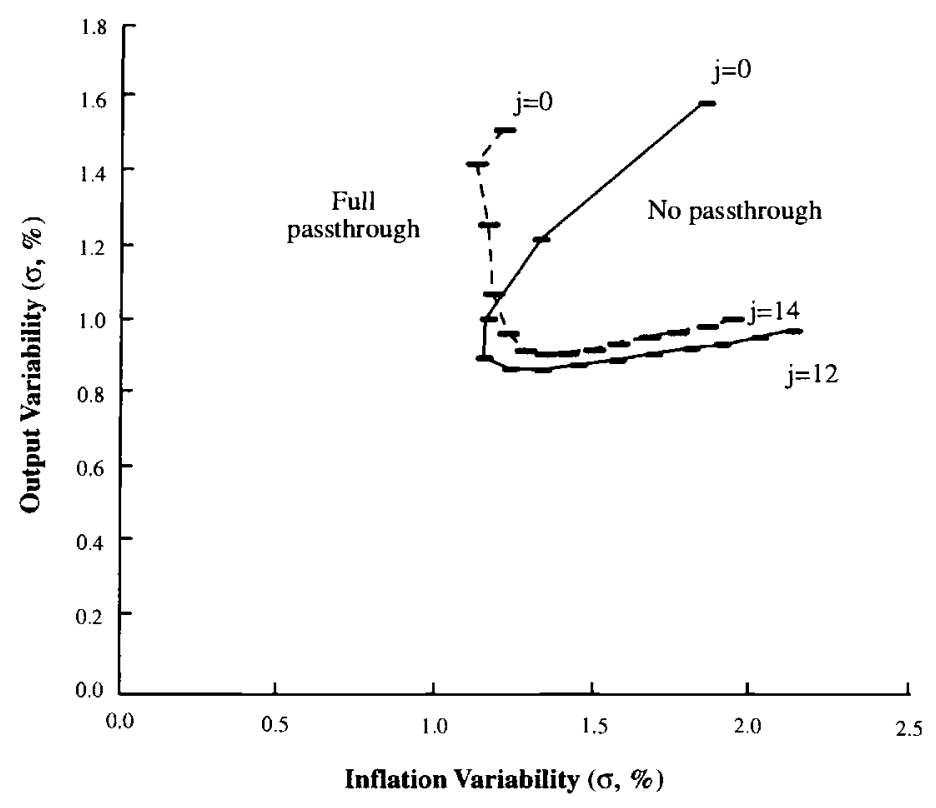

Fig. $4.2 j$-Loci: full- and no-passthrough cases

impact. The (integrals of) real interest and exchange rate changes necessary to hit the inflation target are minimized at this horizon. So too, therefore, is the degree of output destabilization (the integral of output losses). At shorter horizons than this, the adjustment in monetary policy necessary to return inflation to target is that much greater-the upshot of which is a destabilization of output. Once we allow for the fact that central banks in practice feed back from annual inflation rates, whereas our model-based feedback variable is a quarterly inflation rate, the optimal forecast horizon implied by our simulations (of three to six quarters) is rather similar to that used by inflation-targeting central banks in practice (of six to eight quarters). ${ }^{32}$

Second, taking either passthrough assumption, feeding back from a forecast horizon much beyond six quarters leads to worse outcomes for both inflation and output variability. This is the flip side of the arguments used above. Just as short-horizon targeting implies "too much" of a policy response to counteract shocks, long-horizon targeting can equally imply that policy does "too little," thereby setting in train a destabilizing expectational feedback. This works as follows.

Beyond a certain forecast horizon, the effects of any inflation shock have

32. This comparison is also not exact because the two definitions of horizon are different: the feedback horizon in the rule and the policy horizon in practice (the point at which expected inflation is in line with the inflation target) are distinct concepts. 
been damped out of the system by the actions of the central bank: expected inflation is back to target. This implies that, beyond that horizon, our forwardlooking monetary policy rule says "do nothing"; it is entirely hands-off. In expectation, policy has already done its job. But an entirely "hands-off" policy will be destabilizing for inflation expectations - and hence for inflation today - if it is the policy path actually followed in practice. This is because of the circular relationship between forward-looking policy behavior and forwardlooking inflation expectations. The one generates oscillations in the other, which in turn give rise to further feedback on the first. Beyond a certain threshold horizon-when policy is very forward looking - this circularity leads to explosiveness. So this is one general instance in which forward-looking rules generate instabilities: namely, when the forecast horizon extends well beyond the transmission lag. ${ }^{33}$ The possibility of instabilities and indeterminacies arising in forecast-based rules is discussed in Woodford (1994) and Bernanke and Woodford (1997). The mechanism here is very similar.

Third, the main differences between the two passthrough loci show up at horizons less than four quarters. Over these horizons, the full-passthrough locus heads due south, while the no-passthrough locus heads southwest. With incomplete passthrough, policy forward-lookingness reduces both inflation and output variability. This is because inflation transmission lags are lengthier in this particular case. Embodying these (lengthier) lags explicitly in the policy reaction function thus improves inflation control; it guards against monetary policy acting too late. Preemptive policy helps stabilize inflation in the face of transmission lags. At the same time it also helps smooth output, for the reasons outlined above.

The same is generally true in the full-passthrough case, except that most of the benefits then accrue to output stabilization. The gains in inflation stabilization from looking forward are small because inflation control can now be secured relatively quickly through the exchange rate effect on consumption prices. But the gains in output stabilization are still considerable because shorter forecast-horizon targeting induces larger real interest rate and in particular real exchange rate gyrations, with attendant output costs.

All in all, figure 4.2 illustrates fairly persuasively the case for policy forward-lookingness. Using a forecast horizon of three to six quarters delivers far superior outcomes for output and inflation stabilization than, say, currentperiod inflation targeting. Largely, this is the result of transmission lags. Forecast-based rules are, in this sense, lag encompassing. This also provides some empirical justification for the operational practice among inflationtargeting central banks of feeding back from inflation forecasts at horizons beyond one year.

Plainly, the optimal degree of policy forward-lookingness is sensitive to the model (and in particular the lag) specification. In the baseline model, this lag 


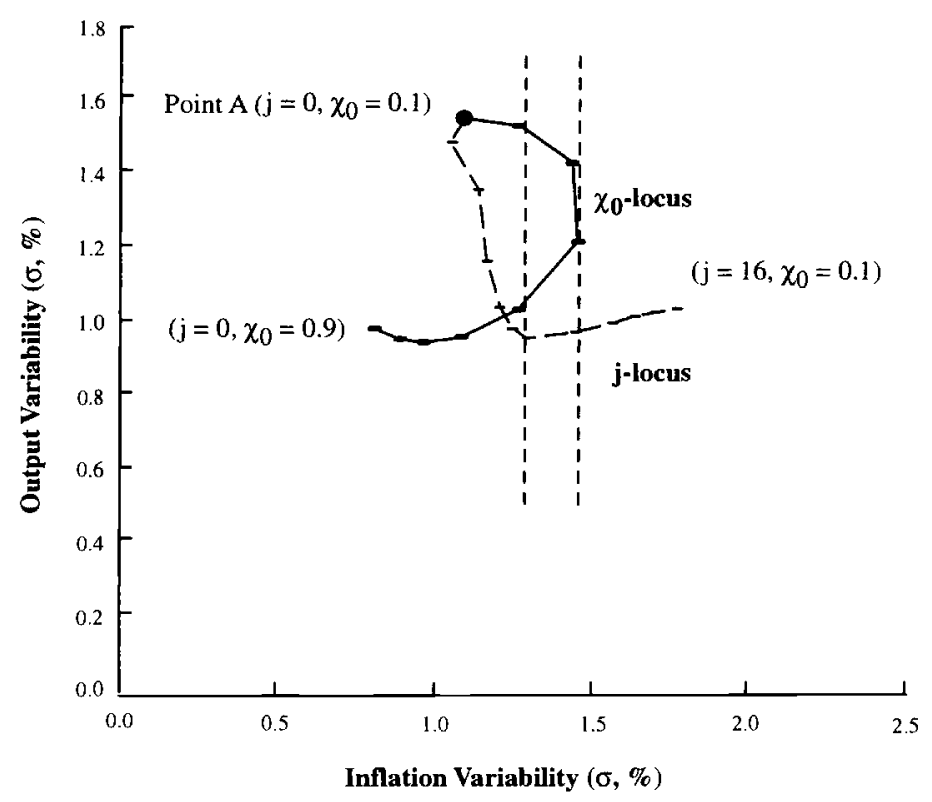

Fig. $4.3 j$-Locus and $\chi_{0}$-locus

structure hinges on the assumed degree of stickiness in wage setting. This stickiness in turn depends on the nature of wage-price contracting and on the degree of forward-lookingness in wage bargaining. Given this, one way to interpret the need for forward-lookingness in policy is that it is serving to compensate for the backward-lookingness in wage bargaining - whether directly through wage-bargaining behavior or indirectly due to the effect of contracting. In a sense, forward-looking monetary policy is acting, in a secondbest fashion, to counter a backward-looking externality elsewhere in the economy. It is interesting to explore this notion further by considering the trade-off between the degree of backward-lookingness on the part of the private sector in the course of their wage bargaining and the degree of forward-lookingness on the part of the central bank in the course of its interest rate setting. ${ }^{34}$

Figure 4.3 illustrates this trade-off. Point $\mathrm{A}$ in figure 4.3 plots the most backward-looking aggregate (wage setting plus policy setting) outcome. The central bank feeds back from current inflation when setting policy $(j=0)$ and wage bargainers assign a weight of only 0.1 to next period's inflation rate when entering the wage bargain $\left(\chi_{0}=0.1\right)$. This results in a very poor macroeconomic outcome, in particular for output variability. In hitting its inflation target, the central bank acts myopically. And the myopia of private sector agents then

34. Equivalently, we could have looked at the effects of altering the length of wage contracting. 
aggravates the effects of bad policy on the real economy through inflation stickiness.

The solid line emanating from point A traces out the locus of outputinflation variabilities as $\chi_{0}$ rises from 0.1 to 0.9 , so that wage bargaining becomes progressively more forward looking. Policy, for now, remains myopic $(j=0)$. In general, the upshot is a welfare improvement. With wages becoming a jump(ier) variable, even myopic policy can bootstrap inflation back to target following shocks. Moreover, wage flexibility means that these inflation adjustments can be brought about at lower output cost. So both inflation and output variability are damped. Fully flexible wages take us closer to a first best. There is little need for policy to then have a forward-looking dimension.

The same is not true, of course, when wages embody a high degree of backward-lookingness. The dashed line in figure 4.3 plots a $j$-locus with $\chi_{0}=$ 0.1 . Though the resulting equilibria are clearly second best in comparison with the forward-looking private sector equilibria, forward-looking monetary policy does now secure a significant improvement over the bad backward-looking equilibrium at point $\mathrm{A}$. In this instance, policy forward-lookingness is serving as a surrogate for forward-looking behavior on the part of the private sector.

Finally, the two vertical lines in figure 4.3 , drawn at $j=6$ and $\chi_{0}=0.3$, indicate degrees of economy-wide forward-lookingness beyond which the economy is unstable. For example, neither of the combinations $\left\{j=6, \chi_{0}=\right.$ $0.4\}$ and $\left\{j=7, \chi_{0}=0.3\right\}$ yields stable macroeconomic outcomes. This suggests that, just as a very backward-looking behavioral combination yields a bad equilibrium (point A), so too does a very forward-looking combination. It also serves notice of the potential instability problems of forecast-based rules. In general, policy forward-lookingness is only desirable as a second-best counterweight to the lags in monetary transmission. The first best is for the lags themselves to shrink - for example, because private sector agents become more forward looking. When this is the case, there is positive merit in the central bank itself not being too forward looking because that risks engendering instabilities.

Figure 4.4 illustrates the above points rather differently. It generalizes the baseline model to accommodate forward-lookingness in the IS curve, following McCallum and Nelson (forthcoming). Specifically, we set (somewhat arbitrarily) $\alpha_{1}=\alpha_{2}=0.5$, so that the backward- and forward-looking output terms in the IS curve are equally weighted. ${ }^{35}$ The solid line in figure 4.4 plots the $j$-locus in this modified model, with the dashed line showing the same for the baseline model.

The modified model $j$-locus generally lies in a welfare-superior location to that under the baseline model, at least at short targeting horizons. For small $j$,

35. McCallum and Nelson's (forthcoming) baseline model has $\left\{\alpha_{1}=0, \alpha_{2}=1\right\}$. That formulation is unstable in our model. 


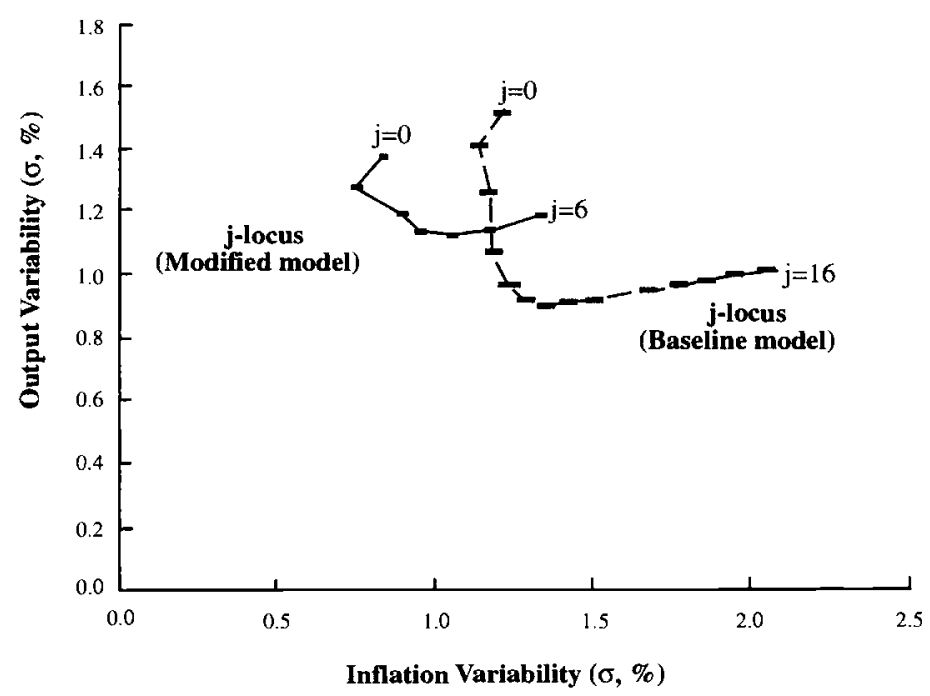

Fig. $4.4 j$-Loci: baseline and modified models

both inflation and output variability are lower in the modified model. Increasing private sector forward-lookingness takes us nearer the first best. Policy forward-lookingness clearly still confers some benefits, since the modified model $j$-locus moves initially to the southwest. But these benefits cease much beyond $j=3$; and beyond $j=6$ the system is explosive. So, again, policy forward-lookingness is only desirable when used as a counterweight to the lags in monetary transmission, here reflected in the backward-looking behavior of the private sector; it is not, of itself, desirable. The less of this intrinsic sluggishness in the economy, the less the need for compensating forwardlookingness through monetary policy.

\subsubsection{Output Encompassing: Output Stabilization through Inflation Targeting}

Although the policy rule (1) contains no explicit output terms, it is already clear that inflation-forecast-based rules are far from output invariant. Figure 4.2 suggests that lengthening the targeting horizon up to and beyond one year ahead can secure clear and significant improvements in output stabilization. Judicious choice of the forecast horizon should allow the authorities, operating according to rule (1), to select their preferred degree of output stabilization.

That is not to say, however, that the output stabilization embodied in policy rules such as rule (1) cannot be improved upon. For example, might not output stabilization be further improved by adding explicit output gap terms to equation (1)? Figure 4.5 shows the effect of this addition. The dashed line simply redraws the full-passthrough $j$-locus from figure 4.2 . The ray emerging from 


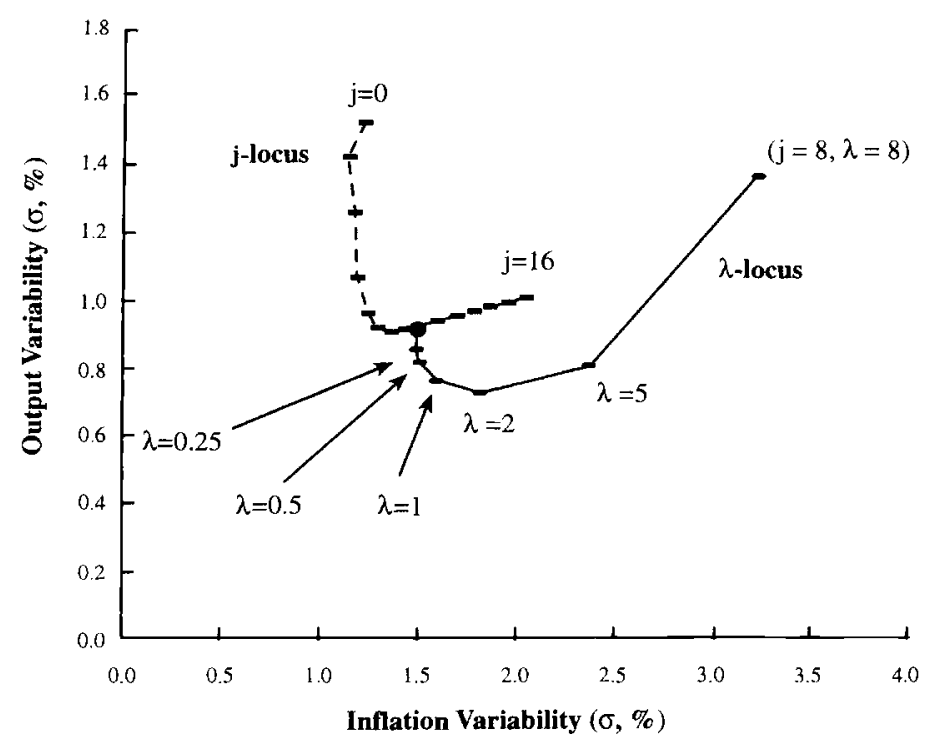

Fig. $4.5 j$-Locus and $\lambda$-locus

this line, starting from the base-case horizon $(j=8)$ and moving initially to the south, plots outcomes from a rule that adds output gap terms to rule (1) with successively higher weights. ${ }^{36}$ These weights, denoted $\lambda$, run from 0.1 to 8.37

Two main points are evident from figure 4.5. First, adding explicit output terms to a forward-looking policy rule does appear to improve output stabilization, with no costs in terms of inflation control-provided the weights attached to output are sufficiently small. The ray moves due south for $0<\lambda<1$. Second, when $\lambda>1$ some output-inflation variability trade-off does start to emerge, with improvements in output stabilization coming at the cost of greater inflation variability. Indeed, for $\lambda>2$ we begin to move in a northeasterly direction, with both output and inflation variability worsening. At $\lambda=10$, the system is explosive. In general, though, figure 4.5 seems to indicate that the addition of output gap terms to a forward-looking rule does yield clear welfare improvements for small enough $\lambda$. Put somewhat differently, it appears to suggest that an inflation-forecast-based rule cannot synthetically recreate the degree of output stabilization possible by targeting the output gap explicitly.

However, this conclusion ignores the fact that the feedback coefficient on expected inflation, $\theta$, can also be altered and that this parameter itself influences output stabilization. Figure 4.6 plots a set of $j$-loci varying the value of

36. The corresponding ray in the no-passthrough case is very similar. So we stick here with the full-passthrough base case.

37. Weights much above 8 were found to generate instability; see below. 


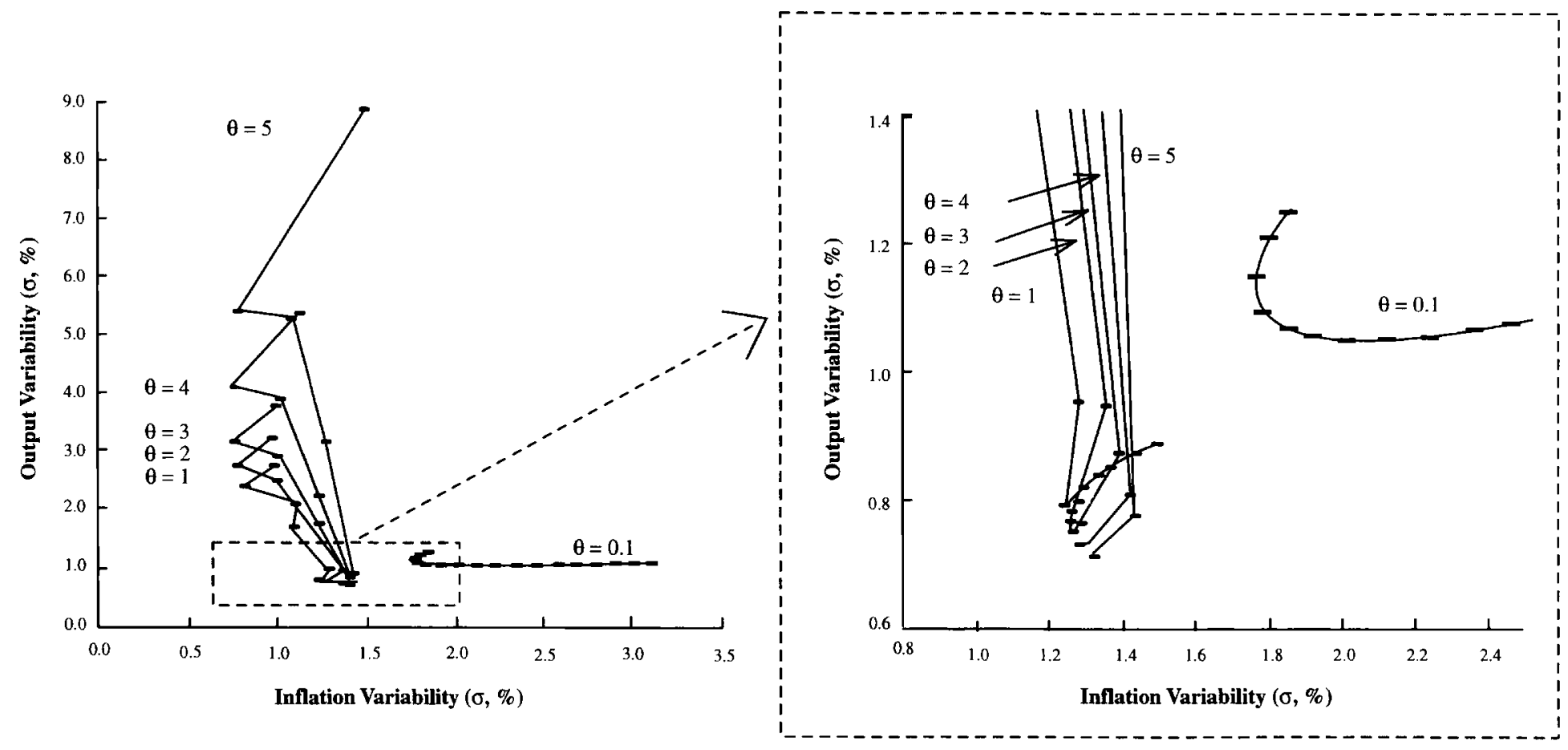

Fig. 4.6 $j$-Loci: $\theta$ varying 
$\theta$ between 0.1 and $5 .^{38}$ Increasing $\theta$ tends to take us in a southwesterly direction; that is, it lowers both output and inflation variability. ${ }^{39}$ Aggressive feedback responses are welfare improving and, in particular, are output stabilizing. This reason is that agents factor this aggressiveness in policy response into their expectations when setting wages. Inflation expectations are thus less disturbed following inflation shocks. Inflation control, via this expectational mechanism, is thereby improved. And with inflation expectations damped following shocks, there is then less need for an offsetting response from monetary policy. As a consequence, output variability is also reduced by the greater aggressiveness in policy responses. ${ }^{40}$

The gains in inflation stabilization are initially pronounced as $\theta$ rises above its 0.5 baseline value. These inflation gains cease-indeed, go into reversebeyond $\theta \approx 1$. Thereafter, most of the gains from increasing $\theta$ show up in improved output stabilization, usually at the expense of some destabilization of inflation. The inflation-forecast-based rule delivering lowest output variability is $\{j=5, \theta=5\}$. This gives a standard deviation of output $\sigma_{y}=0.71$ percent and of inflation $\sigma_{\pi}=1.32$ percent ${ }^{41}$ So can this rule be improved upon by the addition of explicit output terms?

The answer, roughly speaking, is no. Adding an explicit output weight to the rule $\{j=5, \theta=5\}$ yields unstable outcomes. The trajectories that result from adding output terms to other $j$-loci with smaller $\theta$ are shown in figure 4.7. The gain in output stabilization from adding explicit output terms seems to be very marginal. Moreover, it comes at the expense of a significant destabilization of inflation. For example, the parameter triplet $\{j, \theta, \lambda\}$ delivering the lowest output variability is $\{j=5, \theta=4, \lambda=1\}$. This yields $\sigma_{y}=0.69$ percent and $\sigma_{\pi}=1.37$ percent-an output gain of only 0.02 percentage points and an inflation loss of 0.05 percentage points in comparison with the rule that gives no weight to output whatsoever, $\{j=5, \theta=5, \lambda=0\} .{ }^{42}$ It is clear that the optimal $\lambda$ is now smaller even than in the earlier $(\theta=0.5)$ case. Any $\lambda>1$ now takes us into unambiguously welfare-inferior territory. In forward-looking rules there would seem to be benefits from placing a higher relative weight on expected inflation than on output. Indeed, to a first approximation, a weight of zero on output $(\lambda=0)$ comes close to being optimal.

Figure 4.7 suggests that there is, in effect, an output variability threshold at around $\sigma_{y}=0.70$ percent. None of the rules, with or without output gap terms,

38. At values of $\theta>5$, the system was again explosive.

39. This is less clear for high values of $\theta(\theta>1)$. The benefits then tend to be greater for output than for inflation stabilization. Increasing $\theta$ also increases instrument variability, from 0.27 to 1.35 percent as $\theta$ moves from 0.1 to 5 .

40. Higher values of $\theta$ are not always welfare enhancing. Larger values of $\theta$ also increase the diversity of macroeconomic outcomes at extreme values of $j$. For example, current-period inflation targeting $(j=0)$ leads to a very high output variance when $\theta$ is large. And when $j$ is large, high values of $\theta$ increase the chances of explosive outcomes. For example, when $\theta=5$ simulations are explosive beyond a five-quarter forecasting horizon.

41. Output variability is then considerably lower than in the $\{j=8, \theta=0.5\}$ base case $\left(\sigma_{y}=\right.$ 0.93 percent).

42. It also raises instrument variability from 1.8 to 1.92 percent. 


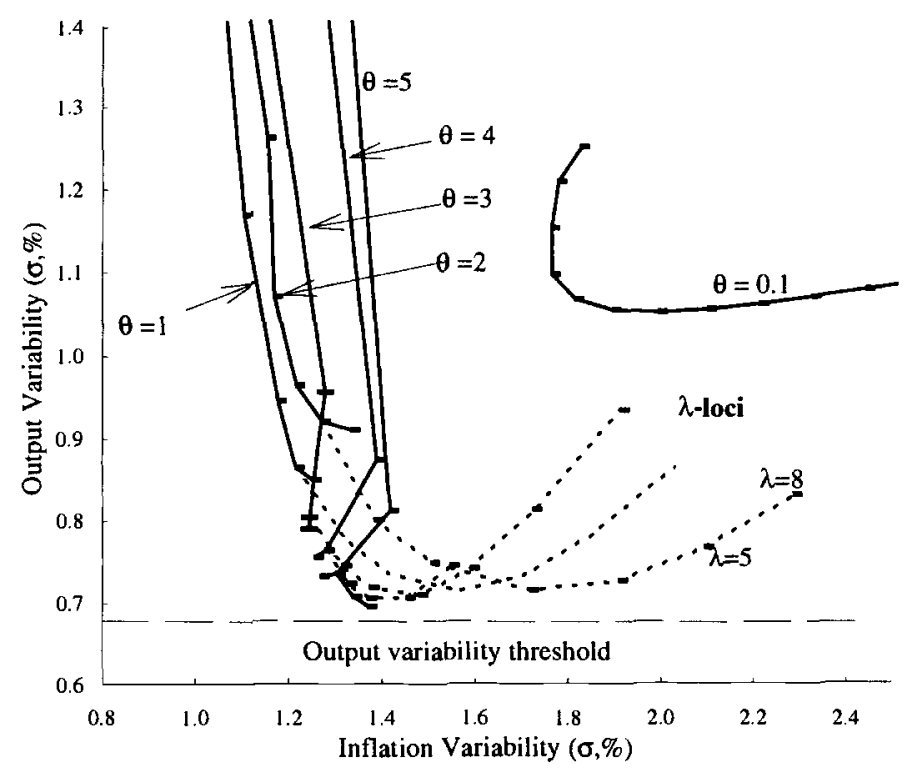

Fig. 4.7 Output variability threshold

can squeeze output variability much beyond that threshold. By appropriate choice of $\{j, \theta\}$, inflation-forecast-based rules appear capable of taking us to that threshold, give or take a very small number. Almost any amount of output smoothing can be synthetically recreated with an inflation-only rule. Forecastbased rules are, in this sense, output encompassing. Inflation nutters and output junkies may disagree over the parameters in rule (1)-that is a question of policy tastes. But they need not differ over the arguments entering this rulethat is a question of policy technology.

\subsubsection{Information Encompassing: A Comparison with Alternative Rules}

Another of the supposed merits of an inflation-forecast-based rule is that it embodies-and thus implicitly feeds back from-all information that is relevant for predicting the future dynamics of inflation. For this reason, it may approximate the optimal state-contingent rule. Certainly, by this reasoning, forward-looking rules should deliver outcomes at least as good as rules that feed back from a restrictive subset of information variables, such as output and inflation under the Taylor rule. These are empirically testable propositions.

To assess how close our forecast-based rule takes us to macroeconomic nirvana, we solve for the time-inconsistent optimal state-contingent rule in our system. This is the rule that solves the control problem

$$
\min _{r_{t}} \mathscr{Z}=E \sum_{i=0}^{\infty} \beta^{i}\left[\omega\left(\pi_{t+i}-\pi^{*}\right)^{2}+(1-\omega)\left(y_{t+i}-y^{*}\right)^{2}+\xi r_{t+1}^{2}\right],
$$


Table 4.1

Comparing Optimal (OPT) and Inflation Forecast-Based (IFB $\{j, \theta\})$ Rules (standard deviation $\sigma$ in percent)

\begin{tabular}{llllc}
\hline Rule & $\sigma_{y}$ & $\sigma_{\pi}$ & $\sigma_{r}$ & $\mathscr{L}$ \\
\hline OPT & 0.782 & 1.103 & 1.033 & 41.83 \\
IFB $\{j=0, \theta=0.5\}$ & 1.52 & 1.199 & 0.925 & 76.37 \\
$\operatorname{IFB}\{j=3, \theta=0.5\}$ & 1.07 & 1.17 & 0.61 & 52.61 \\
$\operatorname{IFB}\{j=6, \theta=0.5\}$ & 0.91 & 1.34 & 0.51 & 54.18 \\
$\operatorname{IFB}\{j=9, \theta=0.5\}$ & 0.94 & 1.57 & 0.40 & 68.04 \\
$\operatorname{IFB}\{j=0, \theta=5.0\}$ & 8.86 & 1.49 & 10.33 & 755.8 \\
$\operatorname{IFB}\{j=5, \theta=5.0\}$ & 0.716 & 1.32 & 1.34 & 53.91 \\
\hline
\end{tabular}

Note: The value of the smoothing parameter is $\gamma=0.5$.

where $\omega$ denotes the relative weight assigned to inflation deviations from target vis-à-vis output deviations from trend and $\xi$ is the weight assigned to instrument variability.

Because there are three arguments in the loss function, the easiest way to summarize the performance of the various rules relative to the optimal rule is by evaluating stochastic welfare losses $(\mathscr{L})$, having set common values for the preference parameters $\{\beta, \omega, \xi\}$. We (somewhat arbitrarily) set $\beta=0.998$, $\omega=0.5$, and $\xi=0.1$. So inflation and output variability are equally weighted, and both are given higher weight than instrument variability. Table 4.1 then compares welfare losses from the optimal rule (OPT) with those from two specifications of the inflation-forecast-based (IFB) rule $(\theta=0.5$ and $\theta=5$ ) for various values of $j .{ }^{43}$ Table 4.1 also shows the standard deviations of output, inflation, and (real) interest rates that result from each of these policy rule specifications.

Current-period inflation targeting ( $j=0$ ) clearly does badly by comparison with the optimal rule. For example, the rule $\{j=0, \theta=0.5\}$ delivers welfare losses that are 85 percent larger than the first best. Inflation-forecast-based rules clearly take us much closer-if not all the way - to that welfare optimum. ${ }^{44}$ For example, $\{j=6, \theta=0.5\}$ delivers a welfare loss only 30 percent worse than the optimum. The optimal values of $\{j, \theta\}$ cannot be derived uniquely from table 4.1 , since they clearly depend on the (arbitrary) values we have assigned to the preference parameters $\{\omega, \xi\}$ in the objective function. But for our chosen preference parameters, the best forecast horizon appears to lie between three and six periods, irrespective of the value of $\theta$.

We can also compare these forward-looking rules with a variety of simple, backward-looking Taylor-type formulations, which feed back from contempo-

43. Where the optimal rule, the associated moments of output, inflation, and the interest rate, and the value of the stochastic welfare loss are calculated using the OPT routine of the ACES/ PRISM solution package. See n. 23.

44. As we discuss below, altering the smoothing parameter, $\gamma$, takes us nearer still to the first best. 
Table 4.2

Comparison of Optimal (OPT), Inflation Forecast-Based (IFB $\{j, \theta\}$ ), and Taylor (T1/T2 $\{a, b, c\})$ Rules (standard deviation $\sigma$ in percent)

\begin{tabular}{lcccc}
\hline Rule & $\sigma_{y}$ & $\sigma_{\pi}$ & $\sigma_{r}$ & $\mathscr{L}$ \\
\hline OPT & 0.78 & 1.10 & 1.03 & 41.83 \\
IFB $\{j=6, \theta=0.5\}$ & 0.91 & 1.34 & 0.51 & 54.18 \\
IFB $\{j=5, \theta=5.0\}$ & 0.72 & 1.32 & 1.34 & 53.91 \\
T1 $\{a=2, b=0.8, c=1\}$ & 1.84 & 0.94 & 1.79 & 92.69 \\
T1 $\{a=0.2, b=1, c=1\}$ & 0.86 & 1.56 & 0.99 & 68.22 \\
T1 $\{a=0.5, b=0.5, c=0\}$ & 1.05 & 1.38 & 0.55 & 61.96 \\
T1 $\{a=0.5, b=1, c=0\}$ & 0.92 & 1.46 & 0.72 & 61.97 \\
T1 $\{a=0.2, b=0.06, c=1.3\}$ & \multicolumn{4}{c}{ Unstable } \\
T2 $\{a=2, b=0.8, c=1\}$ & 2.24 & 1.02 & 2.44 & 130.9 \\
T2 $\{a=0.2, b=1, c=1\}$ & 1.11 & 1.58 & 1.40 & 82.44 \\
T2 $\{a=0.5, b=0.5, c=0\}$ & 1.11 & 1.38 & 0.56 & 64.48 \\
T2 $\{a=0.5, b=1, c=0\}$ & 0.99 & 1.44 & 0.76 & 64.21 \\
T2 $\{a=0.3, b=0.08, c=1.3\}$ & \multicolumn{4}{c}{ Unstable } \\
\hline
\end{tabular}

Note: The value of the smoothing parameter is $\gamma=0.5$.

raneous or lagged values of output and inflation. In particular, for comparability with the other studies in this volume, we consider two types of rule:

$$
\begin{aligned}
& r_{t}=a \pi_{t}+b\left(y_{t}-y_{t}^{*}\right)+c r_{t-1}, \\
& r_{t}=a \pi_{t-1}+b\left(y_{t-1}-y_{t-1}^{*}\right)+c r_{t-1},
\end{aligned}
$$

for a variety of values of $\{a, b, c\}$ listed below. ${ }^{45}$ We classify the first $\mathrm{T} 1\{a, b$, $c\}$ rule and the second $\mathrm{T} 2\{a, b, c\}$ rules. The rule $\mathrm{T} 1\{a=0.5, b=0.5, c=$ $0\}$ is of course the well-known Taylor rule. A comparison of these rules with the OPT and IFB rules is given in table 4.2.

We draw several general conclusions from table 4.2. First, looking just at the performance of the backward-looking rules, it appears that placing a higher weight on output than on inflation yields welfare improvements. This is different than was found to be the case with forward-looking rules. Second, because they are based on an inferior (time $t-1$ ) information set, the T2 rules do worse than the T1 rules. The difference in welfare losses is not, however, that great. This suggests that, at least over the course of one quarter, information lags do not impose that much of a welfare cost. Third, both of the rules placing a small weight on output $(b<0.1)$ and a large weight on smoothing $(c>1)$ yield unstable outcomes in our model. Higher weights on output $(b>0.5)$ or lower weights on smoothing $(c<1)$ are necessary to deliver a stable equilibrium. Fourth, even the best performing backward-looking rule-interestingly,

45. One difference from the other exercises is that here the policy instrument is the short-term real (rather than nominal) interest rate. This should not affect the relative performance of the rules. But we have subtracted one from the inflation parameter, $a$, when simulating the backward-looking policy rules to ensure comparability with the other studies. 
the Taylor rule-delivers a welfare outcome almost 50 percent worse than the optimum. By comparison, the best forward-looking rule delivers a welfare loss that is around 30 percent worse than the optimum.

The final conclusion is evidence of the information-encompassing nature of inflation-forecast-based rules. A forward-looking rule conditions on all variables that affect future inflation and output dynamics, not just output and inflation themselves. In the context of our simple open economy model, an important set of additional state variables are (lagged values of) the exchange rate, as well as additional lags of wages and prices. Just as the optimal feedback rule conditions on these state variables, so too will inflation-forecast-based rules. That is not a feature shared by Taylor rules. In larger models than the one presented here, these extra conditioning variables would include those other information variables affecting future inflation dynamics, such as (lagged) asset and commodity prices. These variables will be captured in forward-looking rules, but not in Taylor-type specifications. In general, the larger the model, the more diffuse will be the information sets of Taylor-type and forward-looking rules ${ }^{46}$ The welfare differences between forward- and backward-looking rules are thus also likely to be larger in these bigger models. So while inflationforecast-based rules cannot take us all the way to the first best, in general they seem likely to take us further in that direction than Taylor-type specifications, at the same time as they retain the simplicity and transparency of the Taylortype rules.

\subsubsection{Other Policy Parameters}

Finally, we explore two further design features of inflation-forecast-based rules. First, what is the preferred degree of interest rate smoothing, $\gamma$, in such a rule? And second, how does a regime of price level targeting compare with the inflation-targeting specifications considered so far?

On interest rate smoothing, the solid line in figure 4.8 replots the $j$-locus from the baseline rule. The rays (dotted lines) emanating from this at $j=\{3$, $6,9\}$ periods illustrate how output-inflation variabilities are affected as $\gamma$ varies between zero (no smoothing) and one. These rays are almost horizontal. Instrument smoothing delivers greater inflation stability, with relatively few countervailing output costs. For example, inflation variability is lowered by 33 percent when moving from $\gamma=0$ to $\gamma=1$, for $\{j=6, \theta=0.5\}$. This arises because rules with higher degrees of smoothing deliver more persistent interest rate responses. These policy responses in turn have a larger impact effect on the exchange rate-and hence on inflation itself. ${ }^{47}$ This sharper inflation control comes at some output cost, though our simulations suggest that this cost is fairly small. The benefits of instrument smoothing are smaller (and potentially

46. This is, e.g., what Black et al. (1997) find when simulating the larger scale Bank of Canada Quarterly Projection Model.

47. This is even true-though to a lesser extent-in the no-passthrough case. 


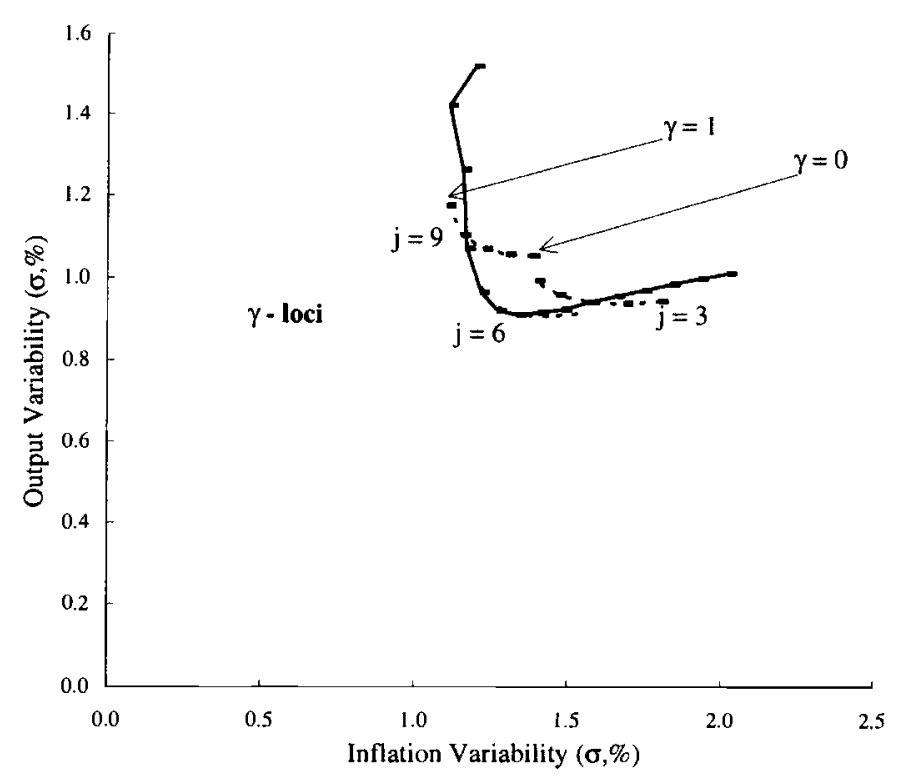

Fig. $4.8 j$-Locus and $\gamma$-locus

trivial) at higher values of $\theta$, however, because policy aggressiveness does the same job as instrument persistence in improving inflation control.

If we evaluate welfare losses using the earlier parameterization of the loss function, then the no-smoothing rule $\{\gamma=0, j=6, \theta=0.5\}$ delivers a welfare loss that is 14 percent higher than that from the high-smoothing rule $\{\gamma=1$, $j=6, \theta=0.5\}$. Indeed, the latter rule now takes us within 25 percent of the optimal rule. So it seems in general that relatively high degrees of interest rate smoothing are welfare enhancing, but that the extent of this welfare improvement may be small if policy is already aggressive.

On price level targeting, our baseline rule now takes the modified form:

$$
r_{t}=\gamma r_{t-1}+(1-\gamma) r_{t}^{*}+\theta\left(E_{t} p_{t+j}^{c}-p^{c *}\right)
$$

Monetary policy now shoots for a deterministic price level path, $p^{c *}$, which we again normalize to zero (in logs). Using the baseline model and the parameter settings $\{\gamma=0, \theta=0.5\},{ }^{48}$ figure 4.9 plots the $j$-locus that results from the price level rule (13). The baseline inflation-forecast-based rule (1) is also shown for comparison (dashed line). For most values of $j$, the price leveltargeting rule delivers welfare-inferior outcomes to the inflation-targeting rule: both output and inflation variability are higher. This is particularly true of short-horizon (e.g., current period) price level targeting. Other studies have 


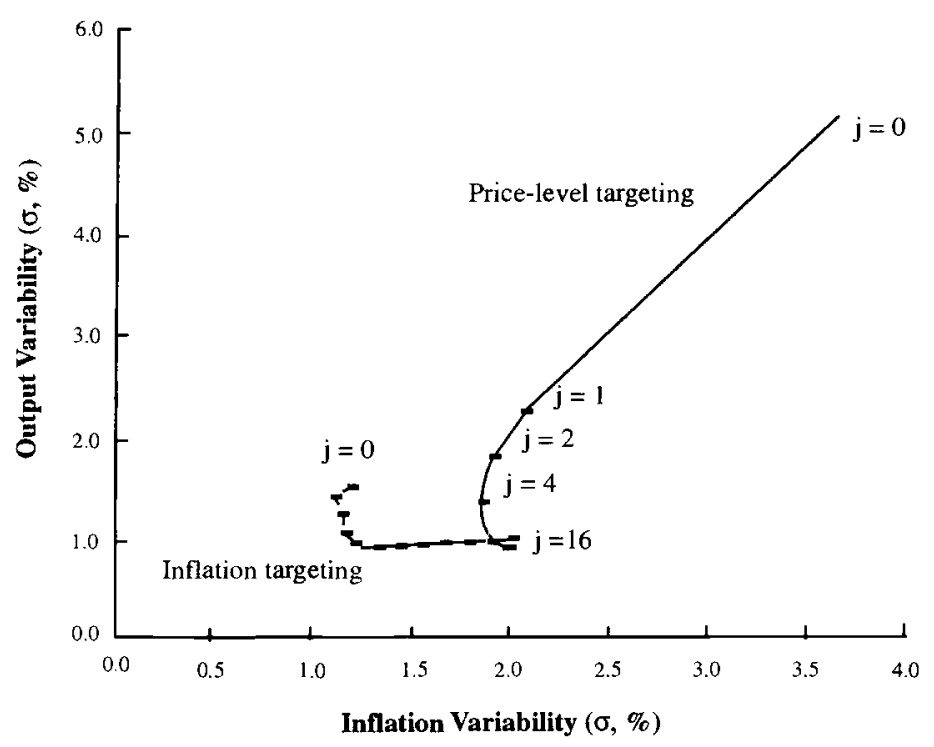

Fig. 4.9 Inflation and price level targeting

also found this to be the case (Duguay 1994; Fillion and Tetlow 1993; Lebow, Roberts, and Stockton 1992; Haldane and Salmon 1995). Nevertheless, for large enough $j$, price-level-targeting rules still perform little worse (and in some cases perhaps better) than inflation-targeting rules.

Moreover, this comparison may unfairly disadvantage price level targeting. The baseline model still embodies a relatively high degree of inflation persistence. It is questionable whether such persistence would survive the move to a monetary regime that delivered price level stationarity. In that situation, price level persistence might be a more realistic specification of price dynamics. In the context of our model, wage contracting might then be better characterized by a conventional Taylor staggered contract wage specification, rather than the Fuhrer-Moore formulation we have used so far. ${ }^{49}$ That is, the contracting equation (6) would be replaced by

$$
w_{t}=\chi_{0} E_{t} w_{t+1}+\left(1-\chi_{0}\right) w_{t-1}+\chi_{1}\left(y_{t}-y_{t}^{*}\right)+\varepsilon_{4},
$$

and the Phillips curve equivalent of equation (8) would now be

$$
\pi_{i}=E_{t} \pi_{t+1}+\chi_{1}\left(y_{t}+y_{t-1}\right)-\rho\left(E_{t} \Delta c_{t+1}\right)+\varepsilon_{5},
$$

where $\rho=(1-\phi) / \phi$. Inflation no longer depends on lagged values; it is a jump variable.

49. Though, in principle, the relative wage formulation of Fuhrer and Moore (1995a) is meant to be a structural relationship, and thus immune to the Lucas critique. 


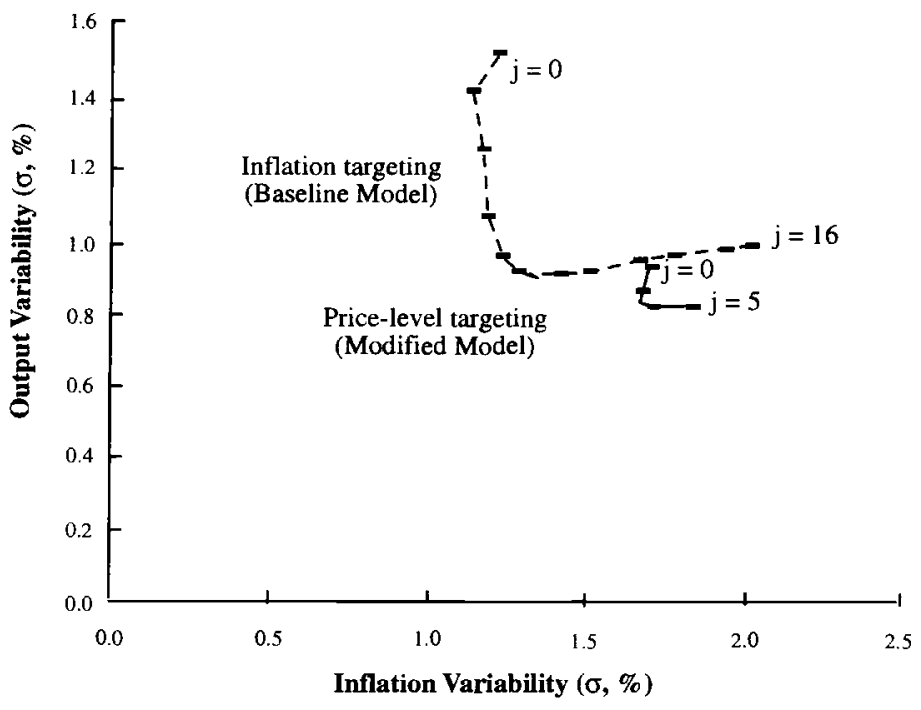

Fig. 4.10 Inflation and price level targeting

The solid line in figure 4.10 plots the $j$-locus for the price level policy rule (13), with equation (15) now replacing equation (8) in the model. This locus clearly lies to the south of the $j$-locus under inflation targeting using the baseline model (dashed line). Price level targeting now does as good (or better) a job of stabilizing output as inflation targeting. This is the result of the increased flexibility in prices. Inflation variability remains higher than under some specifications of inflation targeting, but never excessively so. In sum, even the shortterm output-inflation variability costs of price level targeting appear to be much less pernicious than may have typically been thought likely, under certain parameterizations of the underlying model and policy rule and assuming perfect credibility of such a regime. ${ }^{50}$ For a comprehensive welfare theoretic comparison, the longer term benefits of a price level standard would need to be set against these (potential) short-term costs.

\subsection{Conclusions}

It is widely recognized that monetary policy needs a forward-looking dimension. Inflation-targeting countries have explicitly embodied that notion in the design of their forecast-based policy rules. In principle, these rules confer some real benefits: they embody explicitly transmission lags (lag encom-

50. Williams (1997) and Black et al. (1997) reach similar conclusions in their studies of the United States and Canada, respectively. In a theoretical context, Svensson (1996) also argues that price level targeting need not raise output-inflation variabilities. 
passing); they potentially embody all information useful for predicting future inflation (information encompassing); and, suitably designed, they can achieve a degree of output smoothing (output encompassing). This paper has evaluated quantitatively these features of an inflation-forecast-based rule using simulation techniques. Our main conclusions follow:

1. On lag encompassing, an inflation forecast horizon of three to six quarters appears to deliver the best performance, in the context of our inflationforecast-based policy rules. Shorter horizons than this risk raising both output and inflation variability - the result of policy lags-while longer horizons risk macroeconomic instability. In general, the greater the degree of forwardlookingness on the part of the private sector, the less the compensating need for forward-lookingness by the central bank. These results support the forecast-based approach to monetary policy making pursued by inflation-targeting central banks in practice.

2. An inflation-forecast-based rule, with an appropriately chosen targeting horizon, naturally embodies a degree of output stabilization. Moreover, any degree of output smoothing can be synthetically recreated by judicious choice of the parameters entering an inflation-forecast-based rule. There is no need for any explicit output terms to enter this rule. That is evidence of the outputencompassing nature of inflation targeting based around inflation forecasts.

3. While not taking us all the way to the welfare optimum, forecast-based rules do seem capable of securing welfare-superior outcomes to backwardlooking specifications, the type of which have been the mainstay in the literature to date. That is evidence of the information-encompassing nature of forecast-based policy rules.

We have also evaluated forecast-based price level rules for monetary policy. Under certain parameterizations, they perform creditably even as a short-run macroestabilizer. Perhaps, so soon after having secured low inflation, there is understandable caution about pursuing something as new as a price level standard. Perhaps. Inflation targeting is indeed an embryonic monetary framework, whose performance has yet to be properly tested. But price level targeting, indubitably, is not.

\section{References}

Bakhshi, H., A. G. Haldane, and N. Hatch. 1999. Some costs and benefits of price stability in the United Kingdom. In The costs and benefits of price stability, ed. M. Feldstein. Chicago: University of Chicago Press.

Bernanke, B. S., and F. S. Mishkin. 1997. Inflation targeting: A new rule for monetary policy? Journal of Economic Perspectives 11:97-116.

Bernanke, B. S., and M. Woodford. 1997. Inflation forecasts and monetary policy. Journal of Money, Credit and Banking 29:653-84.

Black, R., T. Macklem, and D. Rose. 1997. On policy rules for price stability. In Price 
stability, inflation targets and monetary policy, ed. Bank of Canada. Ottawa: Bank of Canada.

Blake, A. 1996. Forecast error bounds by stochastic simulation. National Institute Economic Review 64 (May): 72-78.

Blake, A. P., and P. F. Westaway. 1996. Credibility and the effectiveness of inflation targeting regimes. Manchester School 64:28-50.

Blanchard, O. J., and C. M. Kahn. 1980. The solution of linear difference models under rational expectations. Econometrica 48:1305-11.

Blinder, A. S. 1997. What central bankers could learn from academics-and vice versa. Journal of Economic Perspectives 11:3-19.

Brouwer, G. de, and J. O'Regan. 1997. Evaluating simple monetary-policy rules for Australia. In Monetary policy and inflation targeting, ed. P. Lowe. Sidney: Reserve Bank of Australia.

Bryant, R. C., P. Hooper, and C. Mann. 1993. Evaluating policy regimes. Washington, D.C.: Brookings Institution .

Buiter, W. H., and I. Jewitt. 1981. Staggered wage setting with real wage relativities: Variations on a theme of Taylor. Manchester School 49:211-28.

Clarida, R., J. Galí, and M. Gertler. 1998. Monetary policy rules in practice: Some international evidence. European Economic Review 42:1033-67.

Clarida, R., and M. Gertler. 1997. How the Bundesbank conducts monetary policy. In Reducing inflation: Motivation and strategy, ed. C. Romer and D. Romer. Chicago: University of Chicago Press.

Clark, P., D. Laxton, and D. Rose. 1995. Capacity constraints, inflation and the transmission mechanism: Forward-looking versus myopic policy rules. IMF Working Paper no. 75. Washington, D.C.: International Monetary Fund.

Dale, S., and A. G. Haldane. 1995. Interest rates and the channels of monetary transmission: Some sectoral estimates. European Economic Review 39:1611-26.

Duesenberry, J. S. 1949. Income, savings, and the theory of consumer behaviour. Cambridge, Mass.: Harvard University Press.

Duguay, P. 1994. Some thoughts on price stability versus zero inflation. Ottawa: Bank of Canada. Mimeograph.

Fillion, J.-F., and R. Tetlow. 1993. Zero-inflation or price-level targeting? Some answers from stochastic simulation on a small open-economy macro model. In Economic behaviour and policy choice under price stability, ed. Bank of Canada. Ottawa: Bank of Canada.

Freedman, C. 1996. What operating procedures should be adopted to maintain price stability? In Achieving price stability. Kansas City: Federal Reserve Bank of Kansas City.

Friedman, B. M., and K. N. Kuttner. 1996. A price target for U.S. monetary policy? Lessons from the experience with money growth targets. Brookings Papers on Economic Activity, no. 1:77-146.

Friedman, M. 1959. A program for monetary stability. New York: Macmillan.

Fuhrer, J. C. 1997. The (un)importance of forward-looking behaviour in price specifications. Journal of Money, Credit and Banking 29 (3): 338-50.

Fuhrer, J. C., and G. R. Moore. 1995a. Forward-looking behaviour and the stability of a conventional monetary policy rule. Journal of Money, Credit and Banking 27: $1060-70$.

- 1995b. Inflation persistence. Quarterly Journal of Economics 110:127-59.

Gaines, J., A. Al'Nowaihi, and P. Levine. 1989. ACES package for the solution of onecountry linear rational expectations models. London: London Business School. Mimeograph.

Goodfriend, M., and R. G. King. 1997. The new neoclassical synthesis and the role of 
monetary policy. In NBER macroeconomics annual 1997, ed. B. S. Bernanke and J. J. Rotemberg. Cambridge, Mass.: MIT Press.

Haldane, A. G., ed. 1995. Targeting inflation. London: Bank of England.

. 1997. Designing inflation targets. In Monetary policy and inflation targeting, ed. P. Lowe. Sidney: Reserve Bank of Australia.

- 1998. On inflation-targeting in the United Kingdom. Scottish Journal of Political Economy 45 (1): 1-32.

Haldane, A. G., and C. K. Salmon. 1995. Three issues on inflation targets. In Targeting inflation, ed. A. G. Haldane. London: Bank of England.

Keynes, J. M. 1923. A tract on monetary reform. London: Macmillan.

King, M. A. 1996. Direct inflation targets. Paper presented at the symposium on Geldpolitische in Europe, Frankfurt, April.

. 1997. The inflation target five years on. Bank of England Quarterly Bulletin $37: 434-42$.

Kohn, D. 1995. Comment. In NBER macroeconomics annual 1995, ed. B. S. Bernanke and J. J. Rotemberg, 227-33. Cambridge, Mass.: MIT Press.

Lebow, D. E., J. M. Roberts, and D. J. Stockton. 1992. Economic performance under price stability. Working Paper no. 125. Washington, D.C.: Board of Governors of the Federal Reserve System.

Leeper, E. M., C. A. Sims, and T. Zha. 1996. What does monetary policy do? Brookings Papers on Economic Activity, no. 2:1-63.

Leiderman, L., and L. E. O. Svensson, eds. 1995. Inflation targets. London: Centre for Economic Policy Research.

Mayes, D., and B. Chapple. 1995. Defining an inflation target. In Targeting inflation, ed. A. G. Haldane. London: Bank of England.

McCallum, B. T. 1988. Robustness properties of a rule for monetary policy. CarnegieRochester Conference Series on Public Policy 29:172-203.

McCallum, B. T., and E. Nelson. Forthcoming. An optimizing $I S-L M$ specification for monetary policy and business cycle analysis. Journal of Money, Credit, and Banking 31 .

Orphanides, A. 1998. Monetary policy rules based on real-time data. Finance and Economics Discussion Paper no. 98-03. Washington, D.C.: Board of Governors of the Federal Reserve System.

Reifschneider, D. L., D. J. Stockton, and D. W. Wilcox. 1996. Econometric models and the monetary policy process. Washington, D.C.: Board of Governors of the Federal Reserve System. Manuscript.

Reserve Bank of New Zealand. 1997. Monetary policy statement 1997. Wellington: Reserve Bank of New Zealand.

Roberts, J. M. 1995. New Keynesian economics and the Phillips curve. Journal of Money, Credit and Banking 27:975-84.

Rotemberg, J. J., and M. Woodford. 1997. An optimisation-based econometric framework for the evaluation of monetary policy. In NBER macroeconomics annual 1997, ed. B. S. Bernanke and J. J. Rotemberg. Cambridge, Mass.: MIT Press.

Svensson, L. E. O. 1996. Price level targeting versus inflation targeting: A free lunch? NBER Working Paper no. 5719. Cambridge, Mass.: National Bureau of Economic Research.

- 1997a. Inflation-forecast targeting: Implementing and monitoring inflation targets. European Economic Review 41:1111-46.

1997b. Inflation targeting: Some extensions. NBER Working Paper no. 5962. Cambridge, Mass.: National Bureau of Economic Research. nomics.

. Forthcoming. Open-economy inflation targeting. Journal of International Eco- 
Taylor, J. B. 1980. Aggregate dynamics and staggered contracts. Journal of Political Economy 88:1-24.

1993. Discretion versus policy rules in practice. Carnegie-Rochester Conference Series on Public Policy 39:195-214.

Thomas, R. S. 1996. Understanding broad money. Bank of England Quarterly Bulletin 36:163-79.

Williams, J. 1997. Simple rules for monetary policy, Washington, D.C.: Board of Governors of the Federal Reserve System. Manuscript.

Woodford, M. 1994. Nonstandard indicators for monetary policy: Can their usefulness be judged from forecasting regressions? In Monetary policy, ed. N. Gregory Mankiw. Chicago: University of Chicago Press.

\section{Comment Donald L. Kohn}

I appreciate this opportunity to discuss the paper by Batini and Haldane. I have a few comments on the paper, and I also want to take this opportunity to talk a bit about the use-or nonuse-of policy rules by policymakers at the Federal Reserve. In both cases, my intent is to raise questions that Batini and Haldane, and other authors working in this area, might consider addressing to better meet the needs of those policymakers.

With regard to the paper, my questions relate to three conclusions of the paper for policymakers-one implicit and the other two explicit: First, central banks should consider the exchange rate channel for policy: open economy effects are important. Second, central banks should be forward looking, but not too forward looking. Third, central banks do not need to include output smoothing explicitly in their reaction functions.

On the first point, I found the open economy aspect of the model useful and appropriate. I thought the authors structured the transmission sensiblyprobably because we tend to view it quite similarly in analysis at the Federal Reserve. The exchange rate has two channels through which to affect inflation-indirectly through net exports and the output gap, and directly through effects on prices-and their interactions influence the dynamics of the response of inflation to monetary policy or to an exchange rate shock. The demand channel will have potentially lasting effects on the inflation rate, while the supply-side price level effect has a mostly temporary impact. Monetary policymakers need to be aware of these differences as they assess incoming data and form new forecasts after an exchange rate change. Moreover, the policy instrument in the model appropriately remains the short-term interest rate, which responds to changes in the exchange rate indirectly through their effect

Donald L. Kohn is director of the Division of Monetary Affairs, Board of Governors of the Federal Reserve System.

The views expressed are the author's and not necessarily those of other Federal Reserve staff or the Board of Governors. 
on the inflation forecast, not in an automatic, predetermined way, as would result if the central bank targeted a monetary conditions index (MCI). The policy response to variations in the exchange rate ought to depend on the reasons for those variations and their consequences. And the MCI arbitrarily elevates exchange rates relative to many other important aspects of financial conditions - for example, credit conditions, bond rates, or equity prices - in the policy process.

Even though the United States is not as open as the United Kingdom, exchange rates have proved to be an important channel of policy influence and a source of shocks - in some cases persisting for some time, as in the 1980s. Exchange rates and the foreign sector play a substantial role in the large-scale models we have at the Federal Reserve Board, but they do not always get the attention they deserve in smaller scale models sometimes used to examine policy strategies.

In this light, I would have benefited from a fuller treatment of the exchange rate channel. The authors begin with some sensitivity analysis of alternative specifications of this channel but do not follow through in the rest of the paper. In addition, as the authors note, the exchange rate shocks are not derived by using a model of exchange rate movements as a baseline, but rather by comparing actual rates to the forecasts of market participants responding to a survey, and the misses are an order of magnitude larger than the other shocks. I wondered whether the market forecasts from which these shocks were drawn were consistent with the underlying model of covered interest arbitrage. Spot exchange rate movements themselves have deviated from the implications of this arbitrage condition over extended periods, presenting challenges to forwardlooking central banks. It would be interesting to know how sensitive the paper's conclusions-for example, about the appropriate forecast horizon for policymaking or the losses from omitting explicit output targets-were to the size and nature of the exchange rate shocks. Among other things, it might help those of us in not quite so open economies judge the generality of the results.

The analysis that produced the second conclusion-that central banks need to be forward looking, but not too much-also was informative and raised questions. When a shock hits the system, something else must change to damp the resulting fluctuations in output and prices. It can be the private sector directly altering its spending and price and wage setting, or it can be the central bank adjusting to its interest rate target, which in turn induces stabilizing private sector behavior. The authors usefully discuss trade-offs in terms of forward-looking behavior to stabilize economies. If the private sector looks ahead, the central bank need not be so forward looking, presumably because private parties anticipating the central bank's eventual response will make decisions that have the effect of offsetting the shock. All the private sector needs to know is how the central bank will react, and it can adapt to a wide range of strengths of reactions, without seriously affecting the volatility of output and inflation. Even central banks that react weakly to inflation forecasts can make 
up for that by persisting in their policy moves. That persistence will get built into asset markets-in this model, the exchange rate- to influence private spending. Central banks need to look well into the future primarily when private spenders are not looking ahead but instead are responding gradually to incoming information. Adaptive expectations tend to produce long lags in the effects of policy changes, and under these circumstances, anticipatory policy can pay important dividends in stabilizing the economy and the inflation rate.

One aspect of the model results was the relatively narrow time frame for forward-looking behavior that produced favorable results. This knife-edge quality raised questions about the characteristics of the model. Obviously, if both the private sector and central bank are mostly backward looking, it will take a while to damp the effects of shocks, which have to get built into actual prices and output to elicit responses. But in this model, the deterioration in performance for backward-looking policies seemed especially marked and stood in contrast to other results at this conference. Moreover, the central bank and the private sector can be too forward looking as well in the model. In effect, stabilizing actions do not occur because all actors are looking beyond the shock to the return of stability. I suspect that excessively forward-looking private and public sectors have not been a cause of economic problems over the years. Perhaps private agents really do rely mostly on recent information to form expectations. And certainly central banks would modify reaction functions if they sensed destabilizing behavior. It would be interesting to see how sensitive the model's results in this regard were to its specifications-in particular, to its version of the central bank reaction function-and how the model would have to be modified to produce more believable outcomes.

The third conclusion I want to comment on concerns the use of a central bank reaction function that includes only the deviation of inflation from its objective. This and other papers show that by altering its response to inflation deviations, the degree of interest rate smoothing, and the length of the targeting horizon, a central bank using only an inflation forecast can come fairly close to replicating the results it would obtain by explicitly including output smoothing among its objectives. Still, it does not follow that excluding the output gap is appropriate. If output smoothing is a legitimate goal of central banks-if the public expects it in the context of pursuing price stability-deviations of output from potential ought to be among the variables the central bank responds to. Welfare losses are likely to be reduced, even if only by a little, and we cannot be certain that larger reductions would not be forthcoming under different model specifications. More fundamentally, I presume these reaction functions represent what the central bank talks about in its reports and testimonies. It is important for the public and financial markets to understand the central bank's motives. Being explicit about output-smoothing goals and the role they play in policy adjustment should promote better policy making, more reenforcing market reactions, and greater public understanding and support.

Several of my questions involved how robust the results in the Batini and 
Haldane paper would be to different parameters and model structures, and uncertainties about the answers to such questions are the principal reasons why in practice monetary policymakers do not, at least consciously, commit to following rules.

Federal Open Market Committee (FOMC) members are regularly given some information on the predictions from monetary policy rules. Among the material they receive before each committee meeting is a chart that shows historic and projected federal funds rates under the staff forecast relative to the results of two conventional backward-looking rules. One is the Taylor rule, the other an estimated version of that rule fitted over the 1987-96 period, including a gradual adjustment of the federal funds rate to its equilibrium level. Each rule is examined under a variety of output and inflation gap measures; alternative measures can make a significant difference in the readings for the federal funds rate. ${ }^{\prime}$ For the estimated rule, members see a one-standard-deviation band related to parameter uncertainty around the national target. Some individual members with a particular interest in rules receive other simulations or rule outcomes done both at the Board and the Reserve Banks.

Members have used this information in two ways. One is as a benchmark for the stance of policy - how is it positioned relative to past committee responses to similar combinations of output and inflation gaps. It has also been used not so much as a guide to the precise numerical target for policy but to structure thinking about the implications of incoming information for the direction of policy action. But, in truth, only a few members look at this or similar information regularly, and the number does not seem to be growing. I would like to take a few minutes to speculate on why this might be, and what general avenues research might take to make these exercises more useful.

Members seem to regard the use of rules to guide policy as questionable in part because they are quite uncertain about the quantitative specifications of the most basic inputs required by most rules and model exercises. They have little confidence in estimates of the size of the output gap, the level of the natural or equilibrium real interest rate, or even the level of the actual real interest rate, since inflation expectations are at best only imperfectly observable. They see enough evidence of changes in the world around them to distrust the estimates of these variables that they get from history, whether that history is embodied in simple means, single-equation reaction functions, or complex empirical models. ${ }^{2}$ And as a consequence of these changes, they do not see their past actions as a very firm guide to current or future policy.

1. Deriving the results from alternative output and inflation gap measures raised some complex issues having to do with the consistency of the natural real interest rate across inflation indexes and over time as relative trends in inflation measures shifted.

2. To be sure, policymakers need to have judgments (at least implicitly) on these variables when they make discretionary policy decisions. But they are freer to allow the full range of recent information to affect these estimates, and they can calibrate their responses to these variables depending on the particular circumstances. 
Let's look at the difficulties with estimating some of these key variables, bearing in mind that what seem like small deviations in a historical context can loom very large to a policymaker considering a 25 or 50 basis point rate adjustment. One important source of uncertainty about output gaps, and to a lesser extent inflation gaps, is data revisions. One of my colleagues finds substantial differences, ranging up to 200 basis points in some quarters, between Taylor rules calculated with data available at the time the decision was made and those calculated with the series that exist several years later (Orphanides 1998). Among other things, such differences raise questions about the efficacy of rules derived from revised data. The output gap is vulnerable to revisions and to uncertainties about the level of potential output. Some revisions after the fact are based partly on the observation that actual inflation did not turn out close to projections based on previous estimates of the gap. These sorts of revisions can make policy that seemed at the time about in line with past experience or a sensible response to the existing situation look very different when viewed in retrospect. Right now, the level and rate of growth of potential output is a major issue and cause of uncertainty in policy deliberations.

Estimates of the equilibrium real short-term rate of interest in effect embody all the information about the economy and economic relationships. They depend on the levels of supply and demand in the economy, their interactions, the behavior of other financial variables, and the responses of spending and prices to these variables. Judging equilibrium real interest rates from simple historical averages is surely wrong, given shifts over time in key supply and demand factors, such as fiscal policy and the behavior of labor markets. Even inferences from more complex models that try to take account of many of these influences are suspect, in light of the necessarily limited amount of information they can incorporate and the evolution of underlying structures and relationships; for example, the decline of availability constraints in credit markets from the lifting of Regulation $Q$ and the growth of credit securitization has probably raised equilibrium real interest rates over the last 20 years.

The conference organizer is to be commended for placing some emphasis on dealing with uncertainty. But it is just a start. We tend to treat each type of uncertainty separately. An investigator may carefully address the risks of structural change and parameter uncertainty in one specific model. Yet another may consider the implications of not knowing which, among several different models, is a better representation of reality. But in fact different sources of uncertainty may interact in complex ways, and policymakers must face them and form judgments all at once. In addition, policymakers often face skewed notions of uncertainty - if a parameter has changed, it is more likely to be in a particular direction suggested by incoming data. Finally, the specification of the loss function itself may be uncertain. How can we be sure in a democracy that the utility of the public can be represented by a quadratic function-so important to our certainty-equivalent results-or that the public would be equally averse to misses on both sides of targets under all circumstances. As I observe FOMC discussions, and worry about the source of potential policy 
errors, I sense that additional research into the conduct of policy under uncertainty would be especially fruitful and welcome.

So policymakers shy away from rule-based decisions because the rules assume they know too much. But rules can also be perceived as assuming policymakers know too little. Policymakers use incoming information to assess the source and persistence of specific shocks. Deviations from expectations are examined for clues as to whether they arise from the supply or demand sides of the economy and whether they are a consequence of a temporary disturbance to an unchanged underlying structure or represent a lasting alteration to parameter values or model structure. In this examination, policymakers use all available information, including much that is outside the structure of typical models. To the extent that they can reach a judgment on the most likely nature of the shock, they can modify the policy response to improve on the outcome of the rule.

Of course, the authors of this paper and others would point out that all this information should be encompassed by forecasts of inflation or output gaps, and that policymakers should just make their best guess about the future and act on it, perhaps modifying the trajectory of action to take account of parameter uncertainty. One reason policymakers might seem hesitant to take this advice can be seen in figure 4C.1. It shows the central tendency of the range of projections by FOMC members and Blue Chip panelists of inflation and unemployment for each of the last few years. These forecasts were made at the middle of the previous year, which comes fairly close to matching the fourto six-quarter-ahead forecasting horizon that falls out of the Batini-Haldane simulations as close to optimal.

As is readily apparent, both policymakers and private forecasters have persistently underestimated the strength of aggregate demand and hence overpredicted the level of the unemployment rate, in the bottom panel. Nonetheless, they have also consistently overpredicted inflation by substantial amounts. (Data that have become available since the conference confirm that these trends continued in 1998.) Apparently, the world has changed in some significant way - or there has been an astounding series of temporary supply shocksand more quickly or persistently than policymakers or professional forecasters could anticipate.

Naturally, as policymakers receive evidence that their knowledge of the structure of the economy is deficient, they have tended to reduce the weight they place on forecasts in making their decisions. In light of the many simulations, not including those of Batini and Haldane, that show that backwardlooking policy is almost as effective as forecast-based policy, perhaps this is not a problem. But I still harbor the suspicion that policymakers trying to look even a bit inaccurately into the future can produce superior outcomes. The private sector in this situation is likely to be at least as confused as the central bank, and hence its actions based on its expectations and forecasts also may not be stabilizing. And even backward-looking policy is hampered by questions about what the output gap actually is or was. This circumstance suggests 


\section{Inflation}

Percent change of the consumer price index, fourth quarter to fourth quarter

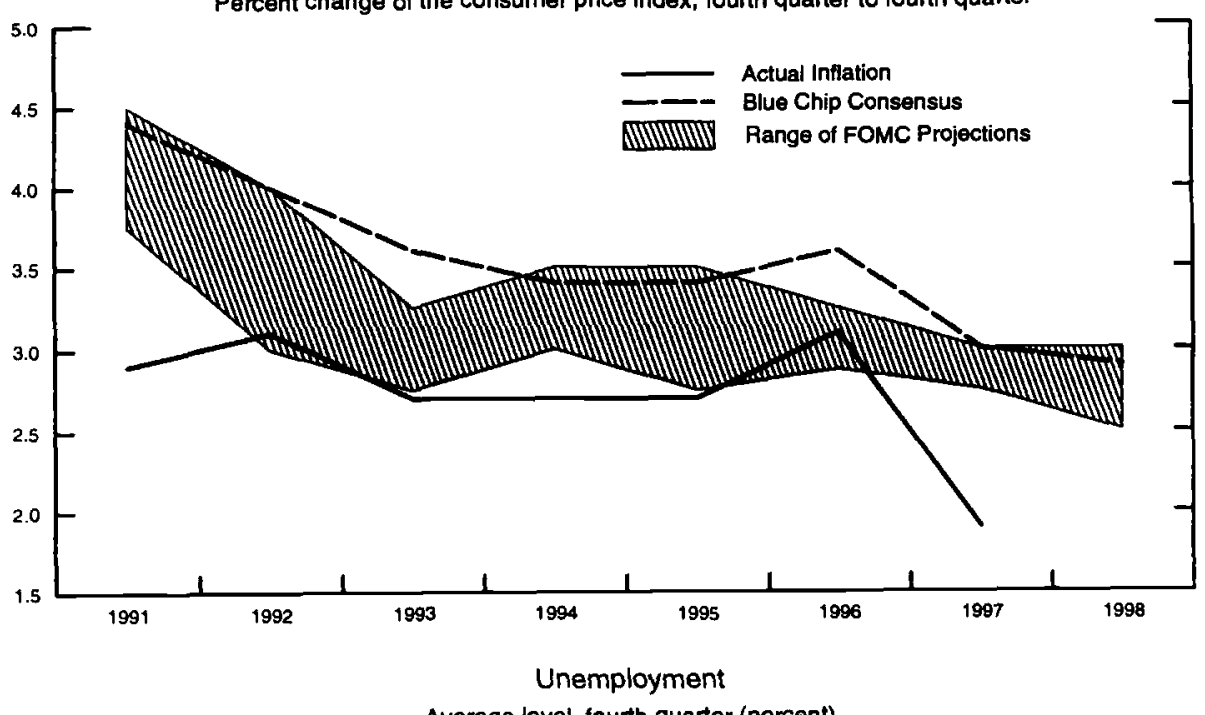

Average level, fourth quarter (percent)

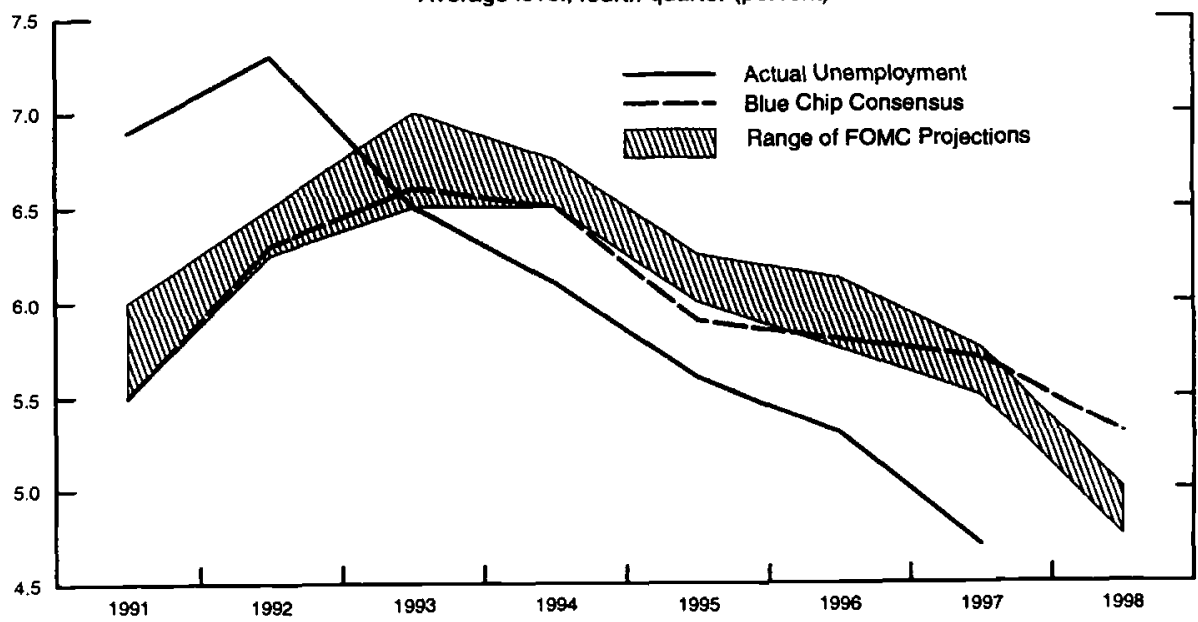

Fig. 4C.1 Inflation and unemployment forecasts from previous July

Note: The FOMC projections are the central tendency of the projections of the governors and reserve bank presidents from the Monetary Policy Report to the Congress on July of the year prior to the year shown. The Blue Chip consensus is from the Blue Chip Economic Indicators published in the same month as the report. 
to me another possible avenue of research, which would examine the interactions between uncertainty and the appropriate weight to be put on forecasts and incoming data.

Finally, I would note that the behavior of asset markets - especially financial asset markets-has contributed substantially to uncertainty about the natural real rate of interest and to central bank decisions to deviate from past patterns of behavior. In these models and reaction functions, the natural rate of interest is an index for a broader array of financial conditions. Batini and Haldane add the exchange rate, which is essential, and others have included long-term interest rates in their models. But over the last 10 years, changes in credit availability and equity prices have played key roles in determining the stance of monetary policy in the United States and elsewhere, for example, Japan. Incorporating richer financial sectors in empirical models and thinking about interactions between asset prices and aggregate demand, inflation, and monetary policy would be another helpful direction to take. And fuller treatment of asset markets would open up another important issue - the implications of divergent views between the central bank and private savers and investors, in contrast to the usual assumption of consistent views held by both the private sector and the central bank. Such divergences are not unusual, and they find expression in actual asset prices that the central bank occasionally finds difficult to justify or understand, and that the central bank anticipates might be corrected at some point, with implications for output and prices.

By noting the impediments to greater rule-based decision making in the central bank, and by suggesting a daunting research agenda, I do not want to leave the impression that the research in the Batini and Haldane paper and more generally at the conference isn't quite productive for monetary policy making. Such research helps to establish theoretical and empirical structures for considering the stance of policy. It pinpoints key variables that should be taken into account when policy is made, and it has something to say about how the size of individual parameters might influence stabilizing monetary policy. It has already provoked some potentially useful debates concerning, for example, the role of forecasts in policy, the strength of policy responses, the place of output gaps in provoking policy actions, the rationale for strings of policy moves, and the effects of uncertainty. Systematic consideration of these issues and others will continue to be useful to policymakers. The Batini and Haldane paper is an interesting addition to this important literature.

\section{Reference}

Orphanides, Athanasios. 1998. Monetary policy rules based on real-time data. Finance and Economics Díscussion Paper no. 98-03. Washington, D.C.: Board of Governors of the Federal Reserve System. 


\section{Discussion Summary}

Andrew Levin noted that the results in both his paper with Wieland and Williams and the Rotemberg and Woodford paper presented at the conference show that for closed economies, there does not seem to be much evidence that model-based inflation forecasts work better than current inflation, the current output gap, and the lagged interest rate. The different results obtained for closed and open economies can in part be explained by the high variance of exchange rate shocks in open economy models. The fundamental mechanism seems to be that forward-looking rules perform better than rules based on current variables in an environment with temporary shocks to inflation. This issue is also related to the length of the horizon considered. The simulation results of all four models in the Levin, Wieland, and Williams paper show that a longer measure of inflation generally works better since temporary shocks are smoothed out automatically. The Batini and Haldane paper only considers onequarter changes in the consumer price index which are very volatile. When four-, eight-, or twelve-quarter changes in prices are used, the advantages of using forecast-based rules disappear.

Michael Woodford remarked that his paper with Rotemberg shows that pure forward-looking rules are far from being optimal. As already mentioned in the comment by Donald Kohn, the familiar intuition that important lags in the effects of monetary policy require rules based on inflation and output forecasts does not work in models with a forward-looking private sector. The first reason for this, common to many models with forward-looking elements (e.g., McCallum-Nelson and Rotemberg-Woodford), is that aggregate demand depends on the long rate of interest, that is, expectations of future short rates, rather than just the current short rate. Therefore, monetary policy has to change people's expectations about future short rates, which is why backward-looking rules for the short rate are not necessarily bad. A second reason, specific to the Rotemberg-Woodford model, is that there are lags in the aggregate demand equation that arise because agents have to use old information in deciding on their spending. For this reason, spending decisions do not depend on past interest rates but on past expectations of current interest rates leading to a lag in the effect of monetary policy. These lags do not have the same implication of wanting the short rate to respond to forecasts, since future aggregate demand does not depend on the current funds rate but on current expectations of future funds rates. According to this setup, only the commitment to changing the federal funds rate in the future has an effect on aggregate demand.

David Longworth noted that there is an underlying tension between the uncertainty of policymakers about the true model of the economy and their desire to include more variables like exchange rates and asset prices in the monetary policy reaction rule. Longworth also stressed that the Bank of England obtains a low variance in inflation without an exchange rate in the policy rule.

Frederic Mishkin wondered about the intuition for the very short horizon of 
the forward-looking rules used in the paper. This might be related to the fact that the paper looks at the United Kingdom, whereas for the United States about two years seem appropriate. Mishkin also asked about the reasons why the Rudebusch and Svensson paper did not find these forward-looking rules as successful as in the present paper. John Taylor asked why the RotembergWoodford rule, or any rule of interest rate smoothing, does not perform well in the paper, even though it uses a forward-looking model. Mark Gertler suggested that a possible answer to these questions consisted in the exchange rate channel, which makes lagged inflation a better forecast of future inflation in a closed economy than in an open economy. 
This Page Intentionally Left Blank 